\title{
Immigration and Native Welfare
}

by

\author{
Gabriel J. Felbermayr \\ Wilhelm Kohler \\ Working Paper No. 0401 \\ February 2004
}

Johannes Kepler University Linz Department of Economics Altenberger Strasse 69 A-4040 Linz - Auhof, Austria

gabriel.felbermayr@jku.at phone +43 (0)70 2468-8265 wilhelm.kohler@jku.at phone +43 (0)70 $2468-8239$ 


\title{
Immigration and Native Welfare
}

\author{
by \\ Gabriel J. Felbermayr ${ }^{1}$ \\ Johannes Kepler University Linz, Austria, and \\ European University Institute Florence, Italy \\ and \\ Wilhelm KOHLER \\ Johannes Kepler University Linz, Austria
}

February 2004

\begin{abstract}
We unify two approaches towards identifying native welfare effects of immigration, one emphasizing the immigration surplus (Borjas, 1995,1999), the other identifying a welfare loss due to terms-of-trade effects (Davis \& Weinstein, 2002). We decompose the native welfare effect of immigration into the standard complementarity effect, augmented by a Stolper-Samuelson effect, and a terms-of-trade effect. Using a structural model with three skill-classes we derive propositions on the wage and native welfare effects of various immigration scenarios. A calibration-based simulation reveals that the size of the inflow and immigrant income repatriation are key determinants of the welfare-ranking of different immigration scenarios.
\end{abstract}

Keywords: international migration, factor movements, international trade, non-tradable goods, welfare analysis, wages, general equilibrium, terms-of-trade.

JEL - codes: F22, F41, J31

Correspondence: Department of Economics, Johannes Kepler University Linz, Altenberger Strasse 69, A-4040 Linz-Auhof, Austria. E-mail: wilhelm.kohler@jku.at; gabriel.felbermayr@jku.at

1 Thanks are due to Guiseppe Bertola, Eric Fisher and Omar Licandro for helpful discussions. Thanks also to David Autor, Herbert Brücker, Michael Burda and Jaap Dronkers for comments and correspondence on related issues.

This research has been conducted under a research project entitled "Public Finance, Unemployment, and Growth" supported by the Austrian Science Fund (FWF) under grant P14702. 


\section{Introduction}

In academic immigration research, economists have mainly concentrated on two questions. How does immigration affect wages and the functional distribution of income in the receiving country? And how does it affect aggregate welfare of the "politically relevant" group of natives, i.e. those who ultimately shape domestic immigration policies? The first question has been tackled in an impressive number of econometric analyses carried out on wage data from different countries and spanning different time periods. Evidence on the mass migration period of 1870-1913 indicates a profound impact on real wages, contributing significantly to international convergence; see O'Rourke \& Williamson (1999) and Chiswick \& Hatton (2003). Studies on post-World-War-II migration have lead to a consensus view that immigration tends to lower wages of competing native workers, but that the effect is small, sometimes even tiny. ${ }^{1}$ However, Borjas (1999) identifies conceptual and econometric problems in this empirical literature, and in Borjas (2003) he uses a refined approach to arrive at much larger effects. His results indicate that an 11 percent increase in US labor supply, as induced by immigration between 1980 and 2000, has depressed average US wages by about 3 percent.

On the second question, there is wide-spread optimism that immigration yields a positive aggregate welfare effect in the host country, based on a complementarity relationship between immigrants and some domestic factors. Typically, this "immigration surplus" is demonstrated in a stylized two-factor, one-sector model, and its magnitude derived by means of calibration-based simulations. Thus, Borjas $(1995,1999)$ calculates for the US that a stock of immigrants equal to 12 percent of the native work force yields a native welfare gain between 0.1 to 0.5 percent of GDP. ${ }^{2}$ However, the simulation also identifies factor price effects which are more pronounced than those found in econometric studies.

\footnotetext{
${ }^{1}$ See Card (2001) for recent evidence, and the surveys by Borjas (1994), Friedberg \& Hunt (1995), Borjas (1999), and Hanson et al. (2002) for the US and DeNew \& Zimmermann (1994) for Europe.

${ }^{2}$ Similar exercises are found in Razin \& Sadka (1997), and Bauer and Zimmermann (1997).
} 
In a recent paper, Davis and Weinstein (2002) challenge the notion of a positive immigration surplus. They argue that a large, technologically superior country is likely to experience a terms-of-trade deterioration from immigration. Calibrating a Ricardian model to US data, they conclude that a 12 percent stock of immigrant labor has caused a 0.8 to 0.9 percent welfare loss for natives. While terms-of-trade effects have already been emphasized in earlier literature on migration, see e.g. Ethier (1985), Davis and Weinstein are the first to provide a quantitative welfare assessment in this context.

These two strands of theory are extreme, both in terms of modeling and message. The positive Borjas-type welfare effect builds on a complementarity relationship between immigrant labor and domestic factors, largely ignoring trade effects of immigration. In contrast, the negative effect in Davis \& Weinstein derives from an immigration-induced worsening of the terms-of-trade in a setup that rules out any complementarity effect.

Given the fact that immigration tends to reduce native workers' wages, and given widespread concern about its fiscal costs in connection with the welfare-state, ${ }^{3}$ advocates of labor immigration bear a heavy burden of political justification. Indeed, a positive immigration surplus almost seems like a necessary condition for any liberal immigration policy based on economic arguments. Once the importance of welfare considerations is recognized, opposing views, such as that of the Borjas-tradition and the Davis-Weinstein-result, certainly warrant further investigation. ${ }^{4}$ This paper proposes an encompassing theoretical framework where the Borjas- and the Davis-Weinstein-results emerge as special cases. We identify several channels responsible for the native welfare effect of immigration and gauge their relative quantitative importance. We allow for different degrees of tradability in factors and goods, ranging from non-tradable goods to perfect integration of capital markets, and we generalize the complementarity-based approach of the Borjas-type to a

\footnotetext{
${ }^{3}$ Welfare-state issues are discussed in Borjas (1994), and more recently in Hanson et al. (2002, ch.12).

${ }^{4}$ In a similar vein, Borjas (2002, p.298) states that “... the immigration literature has paid remarkably little attention to the source and magnitude of the economic gains from immigration. This is one area of study that clearly requires much additional research".
} 
setting with many types of labor and endogenous goods prices. This provides for internal and external adjustment mechanisms which help to bring simulated wage effects closer into line with empirical estimates. Moreover, we allow for alternative values for trade elasticities, including extreme cases where a country approaches a closed, or a small open economy. And finally, we evaluate the role of immigrant income repatriation, which has recently caused renewed attention; see Glytsos (2001) and Chami et al. (2003).

The paper abstracts from the welfare-state and any labor market imperfection. This would seem like a serious omission in the context of international labor mobility. However, our focus is different. Welfare-state issues of immigration are typically treated in abstracting from, or at least grossly simplifying, structural characteristics that may give rise, through adjustment forces on goods and factor markets, to an immigration surplus. The primary aim of our paper is to contribute to a better understanding of how immigration affects natives through these adjustment mechanisms. In proposing a general, though strictly competitive theoretical framework, we hope to pave the ground for the subsequent introduction of additional features reflecting the welfare-state and labor market imperfections. Moreover, our analysis provides a testable link between a country's structural characteristics, such as its size and openness to trade, or the skill content of its trade, and its policy stance on immigration.

The paper is organized in three main sections. In section 2, we propose a general model relying on duality methods to break the native welfare effect of immigration into an "augmented" immigration surplus, which incorporates Stolper-Samuelson-type repercussions in addition to the Borjas-type complementarity effect, and a Davis-Weinstein-type termsof-trade effect. In a multi-labor setting, we show that the complementarity effect no longer needs to be positive, and we derive a set of generalized sufficient conditions under which it is. Moreover, we identify conditions under which the complementarity effect is reinforced by goods price endogeneity.

Section 3 translates the mechanisms identified in section 2 into a structural model which facilitates sharper results, and which paves the way for a quantitative assessment. 
Assuming three types of labor - high-skilled labor, labor with a medium skill level, and unskilled workers - allows us to better reflect stylized facts and key aspects of the policy debate. Introducing a non-tradable good, in addition to tradable goods with finitely elastic export demand, generates a rich pattern of price effects. We illustrate the general equilibrium by means of a novel graphical device which incorporates endogenous price adjustment, bringing together augmented versions of factor price frontiers and labor demand functions, and generating the Borjas- and the Davis-Weinstein-models as special cases.

In section 4, we calibrate our model to a "typical" advanced industrialized country and run simulations for alternative immigration scenarios. The results clearly indicate that the additional channels introduced in sections 2 and 3 are quantitatively important. Moreover, we show that cross-country variations in structural characteristics may indeed be relevant for explaining observed differences in national immigration policies. More specifically, we find that (i) for a given skill-composition of immigration, the native welfare effect is nonmonotonic in the size of the inflow, (ii) for a given size of the inflow, ranking different skillcompositions of immigration with respect to their native welfare effect crucially depends on whether immigrant income is remitted, and (iii) that this ranking is also dependent on the size of the inflow. The final section provides a summary, as well as some normative conclusions and an outlook on further research.

\section{Immigration and welfare: a general treatment}

The global economy features a clear hierarchy of markets regarding the type and degree of internationalization. First, there are non-tradable goods whose prices are determined on strictly national markets. Their share is shrinking, but they continue to play an important role, particularly if immigrant income repatriation drives a wedge between domestic expenditure and domestically generated income. Second, labor markets remain largely national, with immigration mainly governed by quotas. Thirdly, markets for tradable 
goods are characterized by low and falling levels of natural barriers, and national policy discretion is severely limited by international agreements. Hence, unlike wage rates, prices of tradable goods are determined on international markets. Finally, capital markets feature a very high degree of international mobility - at least within the set of industrialized countries - and are governed by parity conditions for risk-adjusted rates of return.

\subsection{Native welfare under perfect capital mobility}

Motivated by these major divides, we model an economy which produces tradable and non-tradable goods, using capital and various types of labor. Perfect international capital mobility means that the economy is price-constrained on capital markets, whereas a quotaoriented immigration policy implies that it is quantity-constrained on labor markets. The underlying assumption is that for all types of labor the economy faces foreign supply which is sufficiently large and elastic, for any quota within the relevant range to be binding. In line with our arguments above, free trade reigns on the tradable goods markets.

Assuming a convex technology of production and perfect competition on goods and factor markets, as well as absence of any other distortion, gross domestic product (GDP), $Y$, can be written as the usual maximum value function ("GDP-function")

$$
Y=y\left(P^{n}, P^{t}, K, L\right), \quad \text { where } K=\bar{K}+K^{*} \text { and } L=\bar{L}+L^{*}
$$

All variables except $Y$ are in vector form, where $P^{n}$ are prices for non-tradables, and $P^{t}$ are domestic prices for tradable goods. $\bar{K}$ is a vector of native ownership of different capital capital stocks, while $K^{*}$ denotes net foreign capital stocks invested in the domestic economy. A negative $K^{*}$ implies outward foreign investments. ${ }^{5}$ By analogy, $\bar{L}$ denotes a vector of domestic labor of various types, while $L^{*}$ indicates stocks of foreign workerresidents, reflecting past immigration flows. We thus make a clear distinction between immigration which relates to the flow $\mathrm{d} L^{*}$, and the stock of foreign worker-residents $L^{*}$.

\footnotetext{
${ }^{5}$ We use upper-case letters to indicate variables, while lower-case letters are functional symbols.
} 
Different types of labor and capital may or may not be specific to sectors. With convex technology, $y$ is convex in prices $\left(P^{n}, P^{t}\right)$, and concave in endowments $(K, L)$.

Competitive supply behavior of this economy satisfies

$$
Q^{n}=y_{P^{n}}\left(P^{n}, P^{t}, K, L\right) \text { and } Q^{t}=y_{P^{t}}\left(P^{n}, P^{t}, K, L\right),
$$

where $Q^{n}$ and $Q^{t}$ are quantities supplied of non-tradable and tradable goods, and a subscript index is used to denote a gradient. Competitive capital rentals $R$ and wage rates $W$ are equal to the corresponding marginal value productivities, i.e.,

$$
R=y_{K}\left(P^{n}, P^{t}, K, L\right) \quad \text { and } \quad W=y_{L}\left(P^{n}, P^{t}, K, L\right) .
$$

Assuming that the number of factors is at least as large as the number of goods, these derivatives exist and are unique, see Neary (1985). Absent any active trade policy, prices $P^{t}$ are equal to world prices. However, in line with Ethier (1985) or Davis \& Weinstein (2002), we allow for $P^{t}$ to adjust endogenously to immigration.

We assume perfect international capital mobility, whence capital stocks $K=\bar{K}+$ $K^{*}$ adjust to satisfy the relevant no-arbitrage conditions. With a given world interest rate $i^{*}$, expressed in terms of some composite consumption good, and abstracting from depreciation, the rental rates of capital are equal to the steady state user cost, $R_{j}=P^{K_{j}} i^{*}$, where $P^{K_{j}}$ is the acquisition price of type- $j$ capital, relative to the composite consumption good. In the remainder, we keep $R$ constant at $\bar{R}$. It proofs useful to introduce a priceconstrained revenue function (see Neary, 1985)

$$
\begin{array}{cl}
g\left(P^{n}, P^{t}, L, \bar{R}\right)= & \max _{Q^{n}, Q^{t}, K}\left[P^{n} Q^{n}+P^{t} Q^{t}-\bar{R} K\right] \\
\text { s.t.: } & Q^{n}, Q^{t} \text { feasible, given } L=\bar{L}+L^{*} \text { and } K .
\end{array}
$$

Given perfect capital mobility, our economy is thus price-constrained on capital markets in that each capital stock adjusts to equate the marginal value productivity of capital with the user cost, i.e.,

$$
y_{K}\left(P^{n}, P^{t}, K, L\right)=\bar{R} \text {. }
$$

This determines endogenous capital stocks $K=k\left(P^{n}, P^{t}, L, \bar{R}\right)$. Notice that domestic ownership of capital stocks, $\bar{K}$, is no longer relevant for production. 
Next we define a native-income-function

$$
y^{n}\left(P^{n}, P^{t}, L, \bar{R}\right)=g\left(P^{n}, P^{t}, L, \bar{R}\right)+\bar{R} \bar{K}-W L^{*} .
$$

Notice that there is a crucial asymmetry between foreign labor and foreign capital: If positive, $K^{*}$ is a truly foreign factor whose income is always repatriated, while foreign worker-residents are national factors and therefore part of GNP. Their income may be remitted, but even if it is not, we do not consider it as native income. This will be of crucial importance when we turn to the welfare measure below. For capital stocks satisfying (5), the envelope theorem implies

$$
\begin{aligned}
y_{P^{j}}\left(P^{n}, P^{t}, K, L\right) & =g_{P^{j}}\left(P^{n}, P^{t}, L, \bar{R}\right)=y_{P^{j}}^{n}\left(P^{n}, P^{t}, L, \bar{R}\right), \quad j=n, t \\
y_{L}\left(P^{n}, P^{t}, K, L\right) & =g_{L}\left(P^{n}, P^{t}, L, \bar{R}\right)=y_{L}^{n}\left(P^{n}, P^{t}, L, \bar{R}\right) .
\end{aligned}
$$

In $(7), g_{P^{j}}\left(P^{n}, P^{t}, L, \bar{R}\right)$ are the supply functions of this capital-price-constrained economy, while $g_{L}\left(P^{n}, P^{t}, L, \bar{R}\right)$ in (8) determines its wage rates for different types of labor as functions of goods prices and the world interest rate, as well as its labor endowment.

From (7) and (8) it follows that the native-income-function for a capital-price-constrained economy has the same standard properties with respect to goods prices and labor endowments, inclusive of foreign worker-residents, as the GDP-function with exogenous capital stocks (quantity-constrained economy). In particular, $g_{L}\left(P^{n}, P^{t}, L, \bar{R}\right)$ is homogeneous of degree zero in $L$, and $g_{L L}\left(P^{n}, P^{t}, L, \bar{R}\right)$ is negative semidefinite, as $g$ inherits concavity in $L$ from $y(\cdot)$ in (1) above. In other words, we may analyze the qualitative effects of immigration without having to pay attention to the role of capital stocks, provided that the world interest rate remains constant. However, from the Le Chatelier-Samuelson principle, it follows that in quantitative terms the price-constraint on capital stocks makes a big difference; see Neary (1985) and section 4 below.

We assume a representative household with an indirect utility function $v\left(P^{n}, P^{t}, E\right)$, where $E$ denotes expenditure. Capital income is always repatriated. If immigrant income is remitted as well, we speak of a "remitted income system" (RIS), else we speak of a "true residence system" (TRS). Domestic demand functions, $d^{n}$ and $d^{t}$, satisfy Roy's identity: 


$$
\begin{aligned}
d^{n}\left(P^{n}, P^{t}, E\right) & =-v_{P^{n}}\left(P^{n}, P^{t}, E\right) / v_{E}\left(P^{n}, P^{t}, E\right) \\
\text { and } d^{t}\left(P^{n}, P^{t}, E\right) & =-v_{P^{t}}\left(P^{n}, P^{t}, E\right) / v_{E}\left(P^{n}, P^{t}, E\right), \\
\text { where TRS implies } E & =y^{n}\left(P^{n}, P^{t}, L, \bar{R}\right)+W L^{*}, \\
\text { while RIS implies } E & =y^{n}\left(P^{n}, P^{t}, L, \bar{R}\right) .
\end{aligned}
$$

We assume a normalization such that $v_{E}(\cdot)=1$ initially. Native welfare $V$ is defined as

$$
V=v\left(P^{n}, P^{t}, Y^{n}\right)=v\left[P^{n}, P^{t}, y^{n}\left(P^{n}, P^{t}, L, \bar{R}\right)\right],
$$

where $Y^{n}$ is native income as defined in (6) above. ${ }^{6}$ Notice that the definition of $v$ is the same for a RIS and a TRS. Native welfare changes according to

$$
\begin{aligned}
\mathrm{d} V & =v_{P^{n}} \mathrm{~d} P^{n}+v_{P^{t}} \mathrm{~d} P^{t}+v_{E} \mathrm{~d} Y^{n} \\
\text { where } \mathrm{d} Y^{n} & =y_{P^{n}}^{n} \mathrm{~d} P^{n}+y_{P^{t}}^{n} \mathrm{~d} P^{t}+y_{\bar{R}}^{n} \mathrm{~d} \bar{R}+y_{L}^{n} \mathrm{~d} L-\mathrm{d}\left(W L^{*}\right) \\
& =Q^{n} \mathrm{~d} P^{n}+Q^{t} \mathrm{~d} P^{t}-K^{*} \mathrm{~d} \bar{R}-L^{*} \mathrm{~d} W \\
\text { hence } \mathrm{d} V & =\left(Q^{n}-D^{n}\right) \mathrm{d} P^{n}+\left(Q^{t}-D^{t}\right) \mathrm{d} P^{t}-K^{*} \mathrm{~d} \bar{R}-L^{*} \mathrm{~d} W
\end{aligned}
$$

The third line assumes that domestic labor endowment changes only through immigration, i.e., $\mathrm{d} L=\mathrm{d} L^{*}$. The marginal effect of a change in the world interest rate on native welfare is given by $-P^{K} K^{*}$, which is the value of the overall net foreign capital stock invested in this economy, whereby $K^{*}<0$ must be interpreted as domestic capital invested abroad. Finally, in the fourth line, by definition we have $Q^{n}=D^{n}$.

We now assume that changes in (14) are driven by immigration, $\mathrm{d} L^{*}>0$, and that $\mathrm{d} \bar{R}=0$. According to (8), domestic wage rates then follow

$$
\mathrm{d} W=g_{L L} \mathrm{~d} L^{*}+g_{L P^{n}} \mathrm{~d} P^{n}+g_{L P^{t}} \mathrm{~d} P^{t},
$$

where $g_{L L}=g_{L L}\left(P^{n}, P^{t}, L, \bar{R}\right)$ is negative semidefinite, due to concavity of $g$ in $L$; see Neary (1985). The term $g_{L P^{n}}=g_{L P^{n}}\left(P^{n}, P^{t}, L, \bar{R}\right)$ is a matrix of Stolper-Samuelson effects of goods prices on wages, and analogously for $g_{L P^{t}}=g_{L P^{t}}\left(P^{n}, P^{t}, L, \bar{R}\right)$.

\footnotetext{
${ }^{6}$ In focusing on native rather than on domestic welfare, we follow a tradition established by Bhagwati \& Srinivasan (1983). This choice also reflects the fact that immigrants are largely excluded from the constituency which is relevant for policy, at least at the time of migration, and possibly a significant time thereafter.
} 


\subsection{The augmented immigration surplus}

In line with the above mentioned hierarchy of markets, we treat $\mathrm{d} L^{*}$ as a policy variable, exogenous to our analysis. By way of contrast, $\mathrm{d} P^{n}$ and $\mathrm{d} P^{t}$ should be seen as endogenous, driven by $\mathrm{d} L^{*}$. The next section will introduce a stylized model which facilitates explicit solution for these price changes for alternative specific immigration flows $\mathrm{d} L^{*}$. At this stage, we simply write $\mathrm{d} P^{n}=\varphi_{L}^{n} \mathrm{~d} L^{*}$ and $\mathrm{d} P^{t}=\varphi_{L}^{t} \mathrm{~d} L^{*}$, where $\varphi_{L}^{n}$ and $\varphi_{L}^{t}$ are matrices of reduced form, general equilibrium derivatives of commodity prices with respect to labor endowments. We may thus write the welfare effect of immigration as

$$
\mathrm{d} V=-L^{*}\left(g_{L L}+g_{L P^{n}} \varphi_{L}^{n}+g_{L P^{t}} \varphi_{L}^{t}\right) \mathrm{d} L^{*}+\left(Q^{t}-D^{t}\right) \varphi_{L}^{t} \mathrm{~d} L^{*}
$$

The first term in equation (16) may be called the augmented immigration surplus, augmented meaning that the generalized Borjas-type complementarity effect $-L^{*} g_{L L} \mathrm{~d} L^{*}$ is combined with a Stolper-Samuelson mechanism relating changes in factor prices to goods prices, whether for tradable or non-tradable goods. Together with the Davis-Weinsteintype terms-of-trade effect in the second term, the augmented surplus determines the native welfare effect of immigration.

The augmented surplus in (16) reveals that native welfare increases if migration changes domestic wages in such a way that income of domestic non-native workers falls. The term is zero if $L^{*}=0$, reflecting the second-order (or infra-marginal) nature of the effect; see Berry and Soligo (1969). The above representation of this surplus looks at marginal units of immigration, but explicitly bringing infra-marginal units $L^{*}$ into the picture. In contrast, the terms-of-trade effect is always a first-order magnitude. Its sign depends on whether immigration tends to increase or decrease domestic excess supply of goods which are exported $\left(Q^{t}-D^{t}>0\right)$ or imported $\left(Q^{t}-D^{t}<0\right)$. Such a first-order welfare effect is ruled out for non-tradables, since by definition we have $Q^{n}-D^{n}=0$. Price changes for non-tradables affect native welfare only indirectly through their wage-effect in the augmented immigration surplus.

The coexistence of a first-order and a second-order effect implies that the native welfare 
effect may be non-monotonic in the size of the labor inflow, given a certain distribution over different types of labor. This is most clearly seen for the simplest case where immigration is restricted to a single type of labor. The second-order derivative $\mathrm{d}^{2} V / \mathrm{d} L^{* 2}$ is then equal to $-\left(g_{L L}+g_{L P^{n}} \varphi_{L}^{n}+g_{L P^{t}} \varphi_{L}^{t}\right)$, provided we accept equation (16) as a linearized approximation. Typically, this term is positive. In contrast, an adverse terms-of-trade effect implies that $\varphi_{L}^{t}<0$, so that the differential (16) is a combination of a convex positive term and a linear negative term, suggesting a potential for non-monotonicity. Section 4 provides evidence that this type of non-monotonicity is important empirically.

The notion of a positive Borjas-type complementarity effect relies on a presumption that under certain conditions the term $L^{*} g_{L L} \mathrm{~d} L^{*}$ is negative. It is a general analogue to the notion that employment of immigrant labor occurs along a downward-sloping marginal product (demand) curve. ${ }^{7}$ We can state a general result emerging from equation (16):

Proposition 1 (generalized complementarity) (i) The generalized Borjas-type complementarity effect, $-L^{*} g_{L L} \mathrm{~d} L^{*}$, is strictly positive only if the inflow of immigrants $\mathrm{d} L^{*}$ is such that it changes the composition of domestic labor endowment $L=\bar{L}+L^{*}$. (ii) It is guaranteed to be positive, if the inflow of immigrants $\mathrm{d} L^{*}$ is such that it leaves the composition of $L^{*}$ unchanged and $g$ is strictly concave in $L$.

The proof is as follows. If immigration leaves domestic labor endowment ratios unchanged we have $\mathrm{d} L^{*}=\zeta\left(\bar{L}+L^{*}\right)$, where $\zeta$ is a positive scalar. Since $g_{L}\left(P^{n}, P^{t}, \bar{L}+L^{*}, \bar{R}\right)$ is homogeneous of degree zero in labor endowments, we have $g_{L L} \mathrm{~d} L^{*}=\zeta g_{L L}\left(\bar{L}+L^{*}\right)=0$. This establishes part (i) of the proposition. On the other hand, for immigration to leave the composition of foreign resident-workers unchanged we must have $\mathrm{d} L^{*}=\xi L^{*}$ for some positive scalar $\xi$. In this case we have $L^{*} g_{L L} \mathrm{~d} L^{*}=\xi L^{*} g_{L L} L^{*}$, which is negative if $g$ is strictly concave in $L$. This establishes part (ii) and thus completes the proof.

\footnotetext{
${ }^{7}$ This is the classic view of the immigration surplus; see, for instance, Borjas $(1995,1999)$. For a similar treatment restricted to one type of labor, see Razin \& Sadka (2001).
} 
This proposition substantiates the wide-spread presumption that native factor owners as a whole gain from any factor inflow that occurs in proportions differing from those prevailing within natives. The standard approach pursued by Borjas $(1995,1999)$ identifies the immigration surplus as the effect of a discrete inflow of labor. Proposition 1 is different in that it looks at a marginal inflow, with a pre-existing stock of foreign workers already present in the economy. In principle, the standard surplus may be recovered from the proposition by integrating over $L^{*}$, but the marginal perspective gives rise to a new element. Thus, in contrast to the discrete case, (i) alone is not sufficient for the existence of a positive immigration surplus, due to pre-existing foreign worker-residents $L^{*}$. On the other hand, while (i) plus (ii) together constitute a sufficient condition, condition (ii) is not necessary for the complementarity effect to arise. It merely rules out that additional immigration boosts wage payments to the existing stock of immigrants via complementarity, thereby reducing the surplus available to natives. In contrast to the results in Borjas, the term $L^{*} g_{L L} d L^{*}$ can be positive, even if $g_{L L}$ is strictly concave and the inflow does change the composition of the total labor force. Conversely, this also opens up the possibility for the Borjas-type complementarity effect to be negative.

Notice that Rybczynski-type internal reallocation of labor may allow the economy to absorb $\mathrm{d} L^{*}$ at unchanged marginal value productivities $g_{L}$, in which case $L^{*} g_{L L} \mathrm{~d} L^{*}=0$. Hence, proposition 1 requires strict concavity in (ii), as this rules out such flat segments of the general equilibrium labor demand functions. The next section will turn to a special model where strict concavity is guaranteed through sector-specificity of factors.

The terms $g_{L P^{n}} \varphi_{L}^{n} \mathrm{~d} L^{*}$ and $g_{L P^{t}} \varphi_{L}^{t} \mathrm{~d} L^{*}$ in equation (16) augment the Borjas-type complementarity effect by changes in wage rates that are associated with goods price adjustments via the Stolper-Samuelson-relationship. Notice that $\varphi_{L}^{t}$ are general equilibrium derivatives of prices with respect to labor endowments. There is an alternative way of interpreting these augmentation terms. Since $g_{P^{t} L}$ and $g_{P^{n} L}$ give the Rybczynski-effect of endowment changes on the outputs of tradable and non-tradable goods, we may call $P^{n} g_{P^{n} L} L^{*}$ the value of non-tradable goods production which is "Rybczynski-attributable" 
to the stock of pre-existing foreign worker-residents; analogously for $P^{t} g_{P^{t} L} L^{*}$ and tradable goods. Together, these terms represent the GDP-loss that the economy would suffer from a loss of all non-native labor, if goods prices did not change. This leads to the following intuitive interpretations of the augmentation in the immigration surplus of (16).

Proposition 2 (augmented immigration surplus) The complementarity-based immigration surplus is reinforced (mitigated) by endogenous changes in goods prices, if these are associated - via the Stolper-Samuelson-relationship - with changes in wage rates such that the attendant change in non-native labor income is negative (positive). Equivalently, the effect is reinforced (mitigated) if goods price adjustments lower (increase) the value of production which is "Rybczynski-attributable" to the stock of foreign worker-residents.

The proof directly follows from (16), recognizing that $L^{*} g_{L P^{t}} \varphi_{L}^{t} \mathrm{~d} L^{*}=L^{*} g_{L P^{t}} \mathrm{~d} P^{t}=$ $\mathrm{d} P^{t} g_{P^{t} L} L^{*}$. Besides causing internal redistribution, the Stolper-Samuelson relationship is thus also relevant for aggregate native welfare. Notice that such an effect always arises if there are non-tradable goods. For tradable goods, the corresponding effect of course vanishes if the country is small on world markets.

\section{Migration and skills: a structural model}

Because of its generality, the model used in the preceding section defies sharp analytical results and is not directly amenable to empirical quantification. Keeping the general assumptions as above, this section implements our main arguments within a simple structural model of the specific-factors-variety. It allows for analytical solutions for goods price changes and paves the way for a calibration-based numerical treatment in section 4 .

Our model structure is inspired by several observations. In most OECD countries, migrants are on average less skilled than natives, and the trend points towards a further deterioration in the relative skill content of immigration. In addition to this skewedness, the skill-distribution of immigration in some countries also exhibits bimodality at the 
high and low ends of the scale. This seems true particularly for the US. ${ }^{8}$ Analyzing such bimodality calls for at least three skill levels. Thus, we break $L$ into high-skilled labor $(H)$, labor with a medium level of skills $(M)$, and unskilled labor $(U)$, so that $L=\{H, M, U\}$, where $H=\bar{H}+H^{*}, M=\bar{M}+M^{*}$ and $U=\bar{U}+U^{*}$, respectively, with associated wage rates $W=\left\{W^{h}, W^{m}, W^{u}\right\}$.

As regards production and trade, our model reflects specialization driven by product differentiation and endowments- and technology-based comparative advantage. This implies that, relative to a well diversified pattern of consumption, production is specialized on a subset of goods, the demand of which is finitely elastic; see Marquez (2002). We model this by assuming three goods, an export good $X$, an import good $Z$, and a nontradable good $N$, and by assuming that residents consume all of these goods, whereas production is specialized in the exportable and the non-tradable good. To the extent that potential immigrants live in subsistence or are unemployed in their home countries, we can safely ignore the implications of immigration for export demand or import supply.

In OECD countries, the non-tradable goods sector, particularly market-oriented activities (construction, services), is typically less skill-intensive than the exportables sector; see e.g. Dimaranan and McDougall (2002). We model this by assuming that exportables use high-skilled labor, alongside medium-skilled labor which is in turn also used in the nontradable sector, together with unskilled labor. Given labor endowment $L=\{H, M, U\}$, outputs in the $X$ - and the $N$-sector are generated according to production functions $Q^{n}=q^{n}\left(U, M^{n}\right)$ and $Q^{x}=q^{x}\left(H, M-M^{x}\right)$, which are linearly homogeneous and strictly concave. This yields a specific-factors structure which has, with varying details, been used extensively in the study of international migration; see Jones (1979), Srinivasan (1983), and - more recently - Razin \& Sadka (1997,2001), and Bilal et al. (2003).

We should like to point out that the model allows for alternative interpretations.

\footnotetext{
${ }^{8}$ See OECD (2001, table 5.8) for evidence based on educational categories, and Jasso et al. (2002) on US bimodality. Bimodality is also observed for some EU countries; see Brücker et al. (2002, p. 24).
} 
First, the formal analysis does not hinge on our skill-intensity assumptions. Opposite assumptions are easily implemented by relabelling sectors and/or labor-types. Secondly, the model may even be interpreted without any reference to skill levels. The fundamental assumption then is that immigrant labor is either specific to the tradable goods sector, or specific to non-tradables goods, while there is a third class of labor which is entirely native and perfectly mobile across both types of goods. Sector-specificity of migrant labor may also be due to regulation pertaining to immigrant employment; see Engerman \& Jones (1997) and Müller (2003).

Preferences are represented, identically for natives and immigrants, by a strictly quasiconcave utility function $u\left(D^{x}, D^{n}, D^{z}\right)$, where $D^{j}$ indicates consumption of good $j$. We denote goods prices by $P^{x}, P^{n}$, and $P^{z}$. Choosing the imported good as our numéraire, we set $P^{z}=1$. The price vector for tradable goods thus appears as $P^{t}=\left\{P^{x}, 1\right\}$. Utility maximization subject to an expenditure constraint, $P D^{n}+P^{x} D^{x}+D^{m} \leq E$, leads to Marshallian demand functions $D^{j}=d^{j}\left(P^{x}, P^{n}, E\right), j=x, n, z$. We add a foreign demand function for good $X, D^{x *}=d^{x *}\left(P^{x}, Y^{*}\right)$, which we allow to be finitely elastic in $P^{x}$. Translating the true residence system (TRS) and the repatriated income system (RIS) of equations (9c) and (9d) into the present context leads to

$$
E=\left\{\begin{array}{ll}
W^{h} H+W^{m} M+W^{u} U+\bar{R} \bar{K}, & \text { if TRS } \\
W^{h} \bar{H}+W^{m} \bar{M}+W^{u} \bar{U}+\bar{R} \bar{K}, & \text { if RIS }
\end{array} .\right.
$$

\subsection{Skill-specific wages and labor endowment}

In equilibrium, profit maximizing labor demands must equal domestic endowments, including native labor and immigrants. Using subscripts for partial derivatives, we have

$$
\begin{aligned}
P^{x} q_{H}^{x}\left(\bar{H}+H^{*}, \bar{M}-M^{n}\right) & =W^{h} \quad \text { and } \quad P^{x} q_{M}^{x}\left(\bar{H}+H^{*}, \bar{M}-M^{n}\right)=W^{m} \\
P^{n} q_{U}^{n}\left(\bar{U}+U^{*}, M^{n}\right) & =W^{u} \quad \text { and } \quad P^{n} q_{M}^{n}\left(\bar{U}+U^{*}, M^{n}\right)=W^{m}
\end{aligned}
$$

The first equation in each line refers to high- and unskilled labor (specific factors), while the second equation relates to mobile labor with medium skills, which features a common wage rate $W^{m}$ in both sectors. Moreover, the endowment constraint implies $M^{x}=\bar{M}-$ 
$M^{n}$, whereby $M^{*}=0$ captures bimodality of migration in skills. Linear homogeneity of $q^{x}(\cdot)$ and $q^{n}(\cdot)$ implies the usual zero-profit conditions: $P^{x}=c^{x}\left(W^{h}, W^{m}\right)$ and $P^{n}=$ $c^{n}\left(W^{u}, W^{m}\right)$, where $c^{x}(\cdot)$ and $c^{n}(\cdot)$ are concave minimum unit-cost functions.

Commodity market equilibrium requires

$$
\begin{gathered}
d^{x}\left(P^{x}, P^{n}, E\right)+d^{* x}\left(P^{x}, Y^{*}\right)=q^{x}\left(\bar{H}+H^{*}, \bar{M}-M^{n}\right) \\
\text { and } d^{n}\left(P^{x}, P^{n}, E\right)=q^{n}\left(\bar{U}+U^{*}, M^{n}\right) .
\end{gathered}
$$

Equations (18) through (21) constitute a system of 6 equations determining 6 endogenous variables: $W^{h}, W^{m}, W^{u}, M^{n}, P^{x}$, and $P^{n}$. Outputs are determined from equilibrium allocation of mobile labor, according to the production functions $q^{x}(\cdot)$ and $q^{n}(\cdot)$. The adding up condition implies $d^{z}\left(P^{x}, P^{n}, E\right) \equiv E-P^{x} d^{x}\left(P^{x}, P^{n}, E\right)-P^{n}\left(P^{x}, P^{n}, E\right)$. Hence, goods markets equilibrium implies current account balance, which reads as as

$$
P^{x} D^{* x}=\left\{\begin{array}{ll}
D^{z}+\bar{R} K^{*}, & \text { if TRS } \\
D^{z}+\left(W^{u} U^{*}+W^{h} H^{*}\right)+\bar{R} K^{*}, & \text { if RIS }
\end{array} .\right.
$$

These expressions state that the value of merchandise exports, $P^{x} D^{* x}$, equals the value of merchandise imports, $D^{z}$, plus the value of net imports of labor and capital services.

\subsection{Immigration, equilibrium domestic wages and native welfare}

We model immigration policy as changes in the domestic supply of high-skilled and unskilled labor, $H$ and $U$. Assuming for simplicity that $U^{*}=0$ and $H^{*}=0$ initially, and assuming stationary domestic labor, we have $\hat{H}=\mathrm{d} H^{*} / H$ and $\hat{U}=\mathrm{d} U^{*} / U$. With $\hat{M}^{*}=0$, bimodality of immigration arises if $\hat{H}>0$ and $\hat{U}>0$. As the augmented immigration surplus is driven essentially by wage effects, we focus on $W^{h}, W^{m}$ and $W^{u}$, carefully observing goods price endogeneity. The above system of equilibrium conditions may be reduced by substituting out goods prices. Dividing the relevant factor market equilibrium conditions in (18) and (19) leads to the familiar equality of relative wage rates and the marginal rates of substitution in each of the two sectors. Inserting the zero profit conditions, $P^{x}=c^{x}\left(W^{h}, W^{m}\right)$ and $P^{n}=c^{n}\left(W^{u}, W^{m}\right)$, into (20) and (21) then 
leaves 4 equilibrium conditions determining the three wage rates, as well as the allocation of mobile labor $M^{n}$.

Equations (23) through (26) state these conditions in differentiated form, using the familiar "hat-notation" to denote relative changes.

$$
\begin{aligned}
\hat{H}+\mu \hat{M}^{n} & =\sigma^{x}\left(\hat{W}^{m}-\hat{W}^{h}\right), \\
\hat{U}-\hat{M}^{n} & =\sigma^{n}\left(\hat{W}^{m}-\hat{W}^{u}\right), \\
-\eta\left[\theta^{x} \hat{W}^{h}+\left(1-\theta^{x}\right) \hat{W}^{m}\right]+\alpha \hat{E}+\hat{\zeta} & =\theta^{x} \hat{H}-\left(1-\theta^{x}\right) \mu \hat{M}^{n}, \\
-\left[\theta^{n} \hat{W}^{u}+\left(1-\theta^{n}\right) \hat{W}^{m}\right]+\hat{E} & =\theta^{n} \hat{U}+\left(1-\theta^{n}\right) \hat{M}^{n} .
\end{aligned}
$$

The first two equations apply the definition of the elasticities of labor substitution in the two sectors, $\sigma^{x}>0$ and $\sigma^{n}>0$, recognizing that full employment of $M$ implies $M^{x}=-\mu \hat{M}^{n}$, where $\mu=M^{x} / M^{n}$. Equations (25) and (26) capture commodity market equilibrium, observing the zero profit conditions in differentiated form: $\hat{P}^{x}=\theta^{x} \hat{W}^{h}+$ $\left(1-\theta^{x}\right) \hat{W}^{m}$ and $\theta^{n} \hat{W}^{u}+\left(1-\theta^{n}\right) \hat{W}^{m}$, where $\theta^{x}$ and $\theta^{n}$ are cost-shares of medium-skilled labor. The equations assume Cobb-Douglas preferences, so that demand for the nontradable good features a unitary price elasticity: $\eta^{n}=1$. This rules out cross-price-effects in demand, hence $\hat{D}^{x}=-\hat{P}^{x}+\hat{E}$. The elasticity of export demand with respect to $P^{x}$ is denoted by $\eta^{*}>0$, whence $\hat{D}^{x *}=-\eta^{*} \hat{P}^{x}+\hat{Y}^{*}$. Overall demand for the exportable good changes according to $-\left[\alpha+(1-\alpha) \eta^{*}\right] \hat{P}^{x}+\alpha \hat{E}+(1-\alpha) \hat{Y}^{*}$. In $(25), \eta$ is defined as $\left[\alpha+(1-\alpha) \eta^{*}\right]$. Note that $\eta \rightarrow \infty$ if $\eta^{*} \rightarrow \infty$. Assuming that immigrants do not contribute to foreign supply or demand, we set $\hat{Y}^{*}=0$; see above.

Equations (23) through (26) determine wage effects $\hat{W}^{l}(l=h, m, u)$ and mobile labor reallocation $\hat{M}^{n}$ from exogenous changes in labor endowments, $\hat{U}$ and $\hat{H}$, as well as from the change in domestic expenditure $\hat{E}$. The latter, however, is endogenous, and determined according to equation (17). This nexus of factor prices and income/expenditure generates substantial complexity. We may, however, obtain significant insights by decomposing the solution. We define $\Omega_{n x}$ as the elasticity of an endogenous variable $n$, $n=\left(M^{n}, W^{h}, W^{m}, W^{u}\right)$, with respect to an immigration-induced change in an exogenous variable, $x=(U, H)$, obtained by solving the subsystem (23) through (26) for constant 
domestic expenditure. Adding the influence of aggregate expenditure on labor allocation $M^{n}$ and factor prices, measured by corresponding elasticities $\Omega_{n E}$, and taking into account the effect of immigration on domestic expenditure, measured by elasticities $\Xi_{E x}$, we arrive at general equilibrium elasticities $\Gamma_{n x}=\Omega_{n x}+\Omega_{n E} \Xi_{E x}$. Notice that domestic expenditure may be affected directly through a change in the domestic work force, and indirectly via immigration-induced factor price changes.

In this section, we focus on the elasticities $\Omega_{n x}$. We apply a graphical tool to characterize the basic mechanisms behind $\Omega_{n x}$ and discuss the above mentioned Borjas- and Davis-Weinstein-models as special cases. The appendix derives the full solution according to the aforementioned decomposition. Moreover, section 4 provides numerical analogues of $\Gamma_{n x}$ for discrete migration flows, focusing among other things on the difference between RIS and the TRS. Assuming expenditure constant is valid even in general equilibrium terms in either of two situations. The first is one where preferences are quasi-linear in the imported good, in which case income changes are absorbed by changes in imports and all income effects disappear in the equilibrium conditions (20) and (21). If the import good is a superior good, this might be a reasonable approximation. Alternatively, one may refer to a case where the government holds (nominal) domestic expenditure constant by means of a suitable macroeconomic policy. The current account would then, of course, no longer be zero across scenarios, but instead adjust endogenously, depending on the income change associated with a certain scenario.

In line with the augmented immigration surplus identified in equation (16), the subsequent analysis relies on a representation of the above equilibrium system by means of augmented factor price (or wage) frontiers, and augmented labor demand schedules.

Augmented wage frontiers: Traditional factor price frontiers depict alternative combinations of factor prices that are consistent with zero profit conditions, given product prices. Our augmented wage frontiers now incorporate the relevant goods market equilibrium, given sector-specific endowments. In the present case there are two such frontiers, 
relating to sectors $X$ and $N$, with sector specific labor endowments $H$ and $U$. Unlike traditional frontiers, the augmented frontiers are not necessarily downward-sloping. For instance, while a fall in $W^{m}$ would facilitate an increase in $W^{h}$ for a given $P^{x}$, the attendant increase in $M^{x}$ depresses the equilibrium goods price and, thus, the rental for the specific factor $H$. Depending on the ease of factor substitution and the price elasticity of demand, $W^{h}$ may in fact fall. A complete analogy obtains for sector $N$. Formal expressions may be obtained by combining (23) and (25), which yields $\mathrm{AWF}^{x}$, as well as combining (24) and (26), which yields $\mathrm{AWF}^{n}$ :

$$
\begin{aligned}
& \hat{W}^{m}=\underbrace{-\frac{\sigma^{x}+\eta \theta^{x} /\left(1-\theta^{x}\right)}{\eta-\sigma^{x}}}_{\omega^{x}} \hat{W}^{h}+\frac{\alpha \hat{E}+\hat{\zeta}-\hat{H}}{\left(1-\theta^{x}\right)\left(\eta-\sigma^{x}\right)}, \\
& \hat{W}^{m}=\underbrace{-\frac{\sigma^{n}+\theta^{n} /\left(1-\theta^{n}\right)}{1-\sigma^{n}}}_{\omega^{n}} \hat{W}^{u}+\frac{\hat{E}-\hat{U}}{\left(1-\theta^{n}\right)\left(1-\sigma^{n}\right)} .
\end{aligned}
$$

The slopes $\omega^{x}$ and $\omega^{n}$ in $\left(\mathrm{AWF}^{x}\right)$ and $\left(\mathrm{AWF}^{n}\right)$ depend on the signs of $\eta-\sigma^{x}$ and $1-$ $\sigma^{n}$, respectively, and the absolute value of these slopes is increasing in the respective elasticities of substitution in labor use, and decreasing in the price-elasticities of demand.

The AWF-schedules capture two opposing forces determining the native welfare effect of immigration. One is the complementarity effect which is responsible for the traditional immigration surplus which decreases with $\sigma$. The other is the price-sensitivity of demand which governs the goods price effects of immigration. Specifically, a low value of $\eta^{*}$ in $\eta \equiv$ $\alpha+(1-\alpha) \eta^{*}$ is conducive to a deterioration of the terms-of-trade, which potentially offsets the complementarity effect. If the country is small, then $\eta \rightarrow \infty$ and the $\mathrm{AWF}^{x}$-locus collapses to a standard factor price frontier, with its elasticity given by $-\theta^{x} /\left(1-\theta^{x}\right)$. On the other hand, if $\sigma^{x} \rightarrow \infty$, then $\omega^{x}$ is 1 , and if $\sigma^{x} \rightarrow 0$ it turns out to be $-\theta^{x} /\left(1-\theta^{x}\right)$. Similar results obtain for $\sigma^{n}$. If the elasticity of substitution and the elasticity of demand coincide, the AWF locus is a vertical line.

The variables $E, \zeta, H$ and $U$ determine the position of the AWF schedules. Changes in domestic or foreign expenditure lead to an upward-shift, if the respective elasticity of substitution is smaller than the elasticity of demand. As more income is available, demand 
increases and goods prices are pushed up, which facilitates higher wage rates. Changes in the supply of specific labor $H$ or $U$, due to immigration, have opposite, but otherwise symmetric effects. The smaller the difference between the elasticity of substitution and the elasticity of supply, the larger the shift of the AWF-curves. If either is infinity, the curves do not shift at all.

Augmented M-labor demand schedules: The augmented demand schedules for mobile labor describe labor demand as functions of $W^{m}$, again incorporating market clearing on the respective goods markets. In inverse and differentiated form we have:

$$
\begin{aligned}
\hat{W}^{m} & =\frac{\alpha \hat{E}+\hat{\zeta}}{\eta}+\theta^{x} \frac{\eta-\sigma^{x}}{\sigma^{x} \eta} \hat{H} \underbrace{-\frac{\eta \theta^{x}+\sigma^{x}\left(1-\theta^{x}\right)}{\sigma^{x} \eta}}_{\varepsilon^{x}} \hat{M}^{x}, \\
\hat{W}^{m} & =\hat{E}+\theta^{n} \frac{1-\sigma^{n}}{\sigma^{n}} \hat{U} \underbrace{-\frac{\theta^{n}+\sigma^{n}\left(1-\theta^{n}\right)}{\sigma^{n}}}_{\varepsilon^{n}} \hat{M}^{n} .
\end{aligned}
$$

Like traditional labor demand schedules, the ALDs are downward-sloping. A high value of $\sigma^{x}$ implies easy substitution between medium- and high-skilled labor in $X$ and, thus, a large quantity reaction upon changes in $W^{m}$. In turn, a large value of $\eta$ makes the marginal value productivity of M-type labor less sensitive to changes in employment. All of this results in a flatter $\operatorname{ALD}^{x}$-curve. As $\eta \rightarrow \infty$, the slope approaches $-\theta^{x} / \sigma^{x}$, and as $\eta \rightarrow 0$, it approaches $-\infty$, regardless of the value of $\sigma^{x}$. On the other hand, as $\sigma^{x} \rightarrow \infty$ the slope approaches $-\left(1-\theta^{x}\right) / \eta$, and if $\sigma^{x}=0$ the slope converges to $-\infty$.

Commodity market clearing may require counter-intuitive shifts upon changes in the stock of the specific factor, the crucial factors again being $\eta-\sigma^{x}$ and $1-\sigma^{n}$. For instance, a sufficiently low price-elasticity of demand coupled with a high elasticity of substitution, $\eta-\sigma^{x}<0$, implies that the marginal value productivity of $M^{x}$ falls as $H$ increases, shifting $\operatorname{ALD}^{x}$ down. Moreover, for a given sign of $\eta-\sigma^{x}$, an increase in the stock of the specific factor shifts the $\mathrm{ALD}^{x}$-curve by a larger amount, the higher the degree of 
complementarity and the smaller the demand elasticity. ${ }^{9}$

Figure 1 illustrates the equilibrium for a given level of domestic expenditure, combining the augmented AWF- and the ALD-lines. The center-panel contains an augmented, Mussa-type "scissors diagram" which pins down the equilibrium allocation of mobile labor $M$ (see Mussa, 1974), while the augmented factor price frontiers relate the mobile factor's wage rate to the remuneration of specific factors $H$ and $U$ in sector $X$ and $N$, respectively. Remember that along these schedules both goods markets are in equilibrium. Labor market equilibrium is identified by the intersection of the augmented labor demand curves, which determines the allocation $M^{n}$ and the wage rate $W^{m}$ of mobile labor. Equilibrium wage rates for $H$ and $U$ are then found on the two augmented factor price frontiers.

Figure 1 shows how immigration of various types affects the AWF - and the ALD-lines. We use a subscript 0 to indicate the initial equilibrium, while subscripts 1 and 2 indicate the new equilibrium under alternative parameter assumptions. First we look at a small open economy, where all goods are tradables with infinite price-elasticities. Immigration then affects domestic welfare through a pure complementarity effect, corresponding to the discrete analogue of the term $L^{*} g_{L L} \mathrm{~d} L^{*}$ in equation (16). The ALD- and AWF-schedules are downward-sloping, and immigration causes vertical shifts by $\left(\theta^{x} / \sigma^{x}\right) \hat{H}$ and $\left(\theta^{n} / \sigma^{n}\right) \hat{U}$, respectively, while leaving the wage frontiers unaffected. Note that a high degree of complementarity (low values of $\sigma^{x}$ and $\sigma^{n}$ ) generates a large ALD-shift.

For the sake of illustration, we focus on a case where $\hat{H}>0$ and $\hat{U}=\hat{M}=0$. Immigration then initiates a reallocation of mobile labor into the $X$-sector, changing $M^{n}$ and driving up $W^{m}$, while pushing down wages for both specific factors. Thus highskilled immigration harms unskilled workers, if mobile resources are drawn away from the sector in which unskilled labor finds employment. The hatched area between the

\footnotetext{
${ }^{9}$ In a similar way, a change in domestic or foreign income shifts the ALD locus up. Via the zero profit condition, higher prices mandate higher wage rates. Note that this effect is zero if $\eta \rightarrow \infty$, whence higher income is absorbed on the goods market without pressure on prices. To avoid unnecessary clutter, we set $\hat{\zeta}=0$ in the remainder of the analysis.
} 
$\mathrm{ALD}_{0}^{x}$ - and the $\mathrm{ALD}_{1}^{x}$-lines, labeled $\left(Y_{1}-Y_{0}\right)$, measures the increase in GDP brought about by such immigration. However, migrant labor $H_{1}^{*}$ as a claim on this according to $W_{1}^{h}$. With constant goods prices, native welfare changes in line with native income, as defined in equation (6). The complementarity-based immigration surplus corresponding to proposition 1 is found as the change in native income $Y_{1}^{N}-Y_{0}^{N}$, which is equal to the triangle $\mathrm{ABC}$. This is recognized by identifying the income gain to M-type labor as $\left(W_{1}^{m}-W_{0}^{m}\right) \bar{M}$, and realizing that this exceeds the loss to specific factors $\bar{H}$ and $\bar{U}$, found as the areas underneath the $\mathrm{ALD}_{0}^{x}$ - and $\mathrm{ALD}_{0}^{n}$-schedules between $W_{1}^{m}$ and $W_{0}^{m}$. The remaining difference, i.e., the aforementioned triangle $\mathrm{ABC}$, measures the Borjastype immigration surplus. Notice, however, that the immigration surplus vanishes if in addition to perfectly elastic demand $-\sigma^{n}$ is infinite. This follows from the previous argument, recognizing from $\left(\mathrm{ALD}^{n}\right)$ that the slope of the $\mathrm{ALD}^{n}$-locus converges to zero as $\sigma^{n} \rightarrow \infty$. We may extend these findings to more general immigration scenarios by means of the following proposition.

Proposition 3 (generalized complementarity) Suppose the economy is small and both goods produced, $X$ and $N$, are tradables, and suppose there is immigration of (sector$X$-specific) high-skilled or (sector-N-specific) unskilled labor, or simultaneous immigration of both types of labor. Then the following holds:

(i) Immigration of whatever pattern is devoid of any wage- or native welfare-effect, if either $\sigma^{x}$ or $\sigma^{n}$ is infinite, and if both goods continue to be produced domestically.

(ii) It unambiguously benefits mobile (medium-skilled) labor, while hurting both highskilled and unskilled labor, if $\sigma^{x}$ and $\sigma^{n}$ are finite.

(iii) If $\sigma^{x}$ and $\sigma^{n}$ are finite, it generates a positive native welfare effect (Borjas).

The formal proof follows from the full solution of system (23) to (26) provided in the appendix. Here we provide some intuition based on figure 1. Note that part (i) of the proposition involves a case with an equal number of goods and factors, hence the zero profit conditions alone determine factor rewards, independently on endowments. Moreover, the 
direction of wage changes is determined by the factor intensity ranking, and does not depend on the magnitudes of the elasticities, provided both are finite. The crucial point in (i) is that a low elasticity of substitution within a sector receiving industry-specific migration is not enough to establish a complementarity-based immigration surplus. If the industry faces perfectly elastic domestic supply of medium-skilled labor which is mobile internally, then the immigration surplus vanishes as well. More generally, reallocation of the mobile factor erodes complementarity in general equilibrium and alleviates the wage pressure in the receiving sector, but only to have it re-appear in the other sector which does not receive any immigration. Of course, this type of adjustment mechanism disappears, if there is a symmetric inflow of both $H$ and $U$-type labor (bimodal immigration). It is apparent from figure 1 that the parameter ratios $\theta^{x} / \sigma^{x}$ and $\theta^{n} / \sigma^{n}$ determine the optimal composition of a given size of labor inflow. We shall return to this in the quantitative exercise of section 4 .

Next, we turn to the case of a finite price-elasticity of export demand, giving rise to what was called augmented complementarity in (16) above. Now we must distinguish between the native income effect, and the native welfare effect of immigration. A lower price of the export good always hurts native income, but lower prices are good for consumers, and the net effect on welfare is given by the final term of equation (16). For a "small change" the net effect for the non-tradable good is always zero, but for "large changes" analogous reasoning applies for non-tradables. In terms of figure 1, the impact of highskilled immigration can be understood as arising in two steps: First the ALD $^{x}$-curve shifts up by the complementarity effect, then it is forced down again by a reduction in $P^{x}$. This latter effect leads to Ricardo-Viner-type redistribution: $W^{m}$ falls, but less than proportionally with $P^{x}$, and $W^{h}$ falls more than proportionally with $P^{x}$. A worsened terms-of-trade is shouldered by three factors, viz. domestic and foreign high-skilled labor, and domestic medium-skilled labor. Unskilled natives, on the other hand, are now better off, relative to the previous (small-country) case, since the price effect as such triggers reallocation of mobile labor into the non-tradables sector. However, as long as $\eta-\sigma^{x}>0$ 
the complementarity effect still dominates the terms-of-trade effect, and the distributional consequences identified in proposition 3 above obtain. Moreover, high-skilled immigration now also affects the $\mathrm{AWF}^{x}$-line, causing a leftward shift to $\mathrm{AWF}_{1}^{x}$; see equation $\left(\mathrm{AWF}^{x}\right)$ above.

Clearly, the condition $\eta-\sigma^{x}=0$ marks a dividing line. This is brought to the fore by the following proposition which still relates to to a pure tradable goods case.

Proposition 4 (augmented complementarity - tradables only) Suppose that both $X$ and $N$ are tradables, and both goods are produced domestically. If $X$ is an export good, with $\eta$ finite, and $N$ is an imported good with a given world price, then the following holds: (i) If $\eta-\sigma^{x}>0$, then the distributional consequences of immigration of whatever pattern are as in proposition 3 (ii) above.

(ii) If $\eta-\sigma^{x}<0$ and $\sigma^{n}$ is finite, and if $X$ is a pure export good, then immigration of (sector-X-specific) high-skilled labor leads to a negative welfare effect (Davis-Weinstein). The immigration loss is accompanied by a reverse internal reallocation of mobile labor into the $N$-sector, and the loss is more than fully accommodated by a real income loss to $H$-tye labor and mobile $M$-type labor, with a real income gain for unskilled labor.

The intuition is easily grasped using figure 1. As above, a given world price of $N$ is equivalent to assuming $\eta^{n} \rightarrow \infty$. Part (i) of the proposition then immediately follows from the reasoning of the previous paragraph, with wage rates for high-skilled and unskilled labor, respectively, falling to $W_{1}^{h}$ and $W_{1}^{u}$. Notice, however, that (i) does not include any statement about welfare. Even if the complementarity effect dominates in that $\eta-\sigma^{x}>0$, native income may fall, since the terms-of-trade deterioration has a direct negative effect on native $H$-type labor income, which is no longer measured underneath the initial $\mathrm{ALD}_{0}^{x}$ line. Thus, if $\mathrm{ALD}_{1}^{x}$ depicts post-migration augmented labor demand, then the triangle $\mathrm{ABC}$ does not depict the change in native income, $Y_{1}^{N}-Y_{0}^{N}$. The potential for a negative native income effect, even for $\eta-\sigma^{x}>0$, is best understood from the proof for part (ii).

Statement (ii) does include a welfare effect for the special case where $X$ is a pure 
export good. This implies $D^{x}=0$ and $\eta=\eta^{*}$. Any native income gain then is equivalent to a welfare gain, and vice versa. Now, let $\eta-\sigma^{x}$ converge to zero. In the limit, there is no vertical shift in the $\mathrm{ALD}^{x}$-schedule. The output effect of an increase in $H$ is completely offset by a deterioration of the terms-of-trade. There is no reallocation of mobile labor, and GDP before and after immigration are the same, which implies that there is a loss in GDP per capita. Moreover, as immigrant wages are paid out of an unchanged GDP, immigration reduces native income. A fortiori, native income is reduced if $\eta-\sigma^{x}<0$, in which case $\mathrm{ALD}^{x}$ shifts down below its initial position, labeled $\mathrm{ALF}_{2}^{x}$ in figure 1. With $\eta^{n} \rightarrow \infty$ and $D^{x}=0$, domestic consumer prices remain constant, and lower native income implies an immigration loss. Moreover, since both $\mathrm{AWF}^{n}$ and $\mathrm{ALD}^{x}$ are downward-sloping, the reallocation and redistribution effects of proposition 4 are readily established. It should be noted that $\eta-\sigma^{x}<0$ implies an upward-sloping initial $\widetilde{\mathrm{AWF}}_{0^{-}}^{x}$ line, which in turn shifts to the left towards $\operatorname{AWF}_{2}^{x}$ upon immigration-induced $\hat{H}$; see equation $\left(\mathrm{AWF}^{x}\right)$ above. Part (ii) of proposition 4 is in some sense equivalent to the case analyzed by Ethier (1985), who considers single-sector, pure export production, but assumes imperfect substitution between domestic and foreign labor, rather than between skill classes. Perhaps more importantly, however, part (ii) of the proposition establishes the Davis-Weinstein-type negative result that we have juxtaposed with the notion of a Borjas-type immigration surplus in the introduction.

Next, we turn to the core interpretation of our model, where $N$ is a non-tradable good, with a unitary price elasticity of demand. There is now also a borderline given by $\sigma^{n}=1$. It is straightforward that part (i) of proposition 4 is upheld if $\sigma^{n}<1$. But the price effect for the non-tradable complicates the welfare analysis. For instance, in the case considered by (ii) of proposition 4, output of the non-tradable good increases and equilibrium requires a fall in $P^{n}$. While this is fully incorporated in the $\mathrm{AWF}^{n}$ - and $\mathrm{ALD}^{n}$-lines, it negates a welfare conclusion from the native income change. However, referring to equation (16) above, we may state the following proposition.

Proposition 5 (augmented complementarity with non-tradables) Suppose that the 
domestic economy produces a pure exportable good $X$, with $\eta$ finite, and a non-tradable good N. Suppose, moreover, that a certain stock of foreign unskilled labor is already present, $U^{*}>0$, while $H^{*}=0$ initially. Then, marginal immigration of ( $X$-specific) high-skilled labor entails a native welfare loss, if $\eta-\sigma^{x}<0$ and $\sigma^{n}$ is finite.

This follows from the previous proposition and equation (16) of the previous section, which shows that at the margin there is no direct welfare effect from any change in $P^{n}$, while the terms-of-trade deterioration constitutes a first-order welfare loss. Notice, however, that for a discrete inflow of high-skilled labor the ensuing fall in the price of the non-tradable good becomes welfare-relevant. The proposition highlights a further case which may be subsumed under the Davis-Weinstein-result mentioned in the introduction.

If $\sigma^{n}>1$ and $\eta-\sigma^{x}<0$, there is complete dominance of price effects. The $\mathrm{AFW}^{n}$-line is upward-sloping, and $\hat{U}>0$ shifts the $\mathrm{ALD}^{n}$-line down. Any inflow of whatever skill pattern causes a fall in all nominal wage rates. This seems like an extreme variant of the Davis-Weinstein-case, but looking at nominal wages alone is not enough for welfare conclusions. Changes in real wages are found by setting the full solutions for $\hat{W}^{h}, \hat{W}^{m}$ and $\hat{W}^{u}$ against price changes according to $\beta^{x} \hat{P}^{x}+\beta^{n} \hat{P}^{n}=\beta^{x}\left[\theta^{x} \hat{W}^{m}+\left(1-\theta^{x}\right) \hat{W}^{h}\right]+$ $\beta^{n}\left[\theta^{n} \hat{W}^{m}+\left(1-\theta^{n}\right) \hat{W}^{u}\right]$, where $\beta^{x}$ and $\beta^{n}$ are the expenditure shares on the export and the non-tradable good; see the appendix. The larger the share of export sales in $X$-output, $1-\alpha$, and the larger at the same time the shares of good $X$ and $N$ in domestic expenditure, $\beta^{x}+\beta^{n}$, the larger the real wage effects for any type of labor. Moreover, the price cut for the non-tradable good, and thus the real wage effect, is larger under the repatriated income system (RIS) than under the true residence system (TRS). Immigration under the RIS, particularly unskilled immigration, boosts supply of the non-tradable good, while immigrant labor income does not contribute to domestic demand. Under the TRS, all immigrant labor income is spent domestically according to uniform preferences, hence there is a direct expansionary demand effect from immigration which clearly mitigates the downward pressure on $P^{n}$; see (17) above. The quantitative importance of such price changes for the native welfare effects of immigration will become apparent in the next 
section which turns to a numerical perspective.

\section{A numerical perspective}

The previous sections have provided a theoretical treatment of some hitherto neglected channels through which immigration affects native welfare. But do they make a difference quantitatively? What are the structural characteristics of an immigration country that make them particularly important? And what are the orders of magnitude that we are talking about? In this section, we pursue a calibration-based numerical analysis which provides tentative answers to these questions. A numerical approach also allows us to extend the substantive focus of our analysis beyond the confines of analytical tractability. Specifically, it facilitates capturing the interdependence between factor prices and aggregate income/expenditure and, thus, to highlight the difference between the two systems of repatriated income (RIS) and true residence (TRS); see the appendix for a full solution.

Turning to a numerical treatment also allows to look at discrete migration flows, in addition to the local results derived above. This seems particularly important, given the above mentioned potential for non-monotonicity of the welfare effect. Moreover, we shall be able to more systematically explore the implications of varying skill-compositions of immigration, such as the bimodal immigration mentioned in the introduction.

A final motivation for the quantitative analysis pursued in this section derives from the significance of capital. Based on a principal insight from section 2, we were able to derive important qualitative insights without explicitly modeling capital in production. The crucial assumption was that all capital stocks are endogenously adjusted under conditions of perfect international capital mobility. However, this view of capital has important quantitative implications. More specifically, the Le Chatelier-Samuelson principle identified in section 2 implies that the wage and associated welfare effects of immigration are dampened, relative to a case where capital stocks are given from domestic endowments. On the other hand, the presence of capital generates additional leverage for welfare ef- 
fects of immigration through endogenous goods price changes. If native capital income is determined by a fixed capital rental $\bar{R}$ from world capital markets and by given domestic capital ownership $\bar{K}$, any reduction in the domestic non-tradable goods price brought about by immigration implies a gain in real terms for a substantial fraction of native income.

\subsection{The calibration approach}

The aim of this section is to put likely orders of magnitude on the wage and welfare effects of alternative conceivable migration scenarios, relying on an empirically relevant parameterization of our model. Even though we do not go as far as analyzing specific proposals for immigration policy, this seems an important first step towards quantification.

We parameterize our model by combining extraneous information on elasticity values, as well as direct observations of key empirical magnitudes, in order determine remaining model parameters from equilibrium conditions, such that the model replicates a realistic data set as a benchmark equilibrium solution. More specifically, we specify $\eta^{*}$ from recent econometric evidence on trade elasticities. For domestic demand we assume Cobb-Douglas preferences, determining budget shares for tradables and non-tradables from observations for a typical OECD (immigration-) country. We use a nested CES-parameterization for technology, relying on recent econometric evidence for elasticities of substitution between capital and labor, as well as between different types of labor. Again, production and costshares are determined from stylized observations for a typical OECD country. As regards initial endowments, we rely on observed labor force skill-distributions. And finally, in order to calibrate benchmark equilibrium wage rates, we utilize observations on functional as well as personal income distribution. The appendix describes further details, including sources, and presents the full benchmark data set in table A.2. 


\subsection{Simulation results}

Given the above discussion, and given the skill-orientation of the immigration policy debate, the scenario design should be organized around the skill-composition of immigration. We therefore consider (1) a perfectly balanced inflow, where the immigrant and native labor force share the same skill-composition so that immigration leaves the relative supply of different skill groups in the host economy unchanged, (2) a simultaneous immigration of high- and unskilled workers ("inflow at tails"), whereby $80 \%$ of the inflow are unskilled workers and $20 \%$ is skilled labor, (3) an inflow of high-skilled workers only, and (4) an inflow only of unskilled workers. To ensure comparability with the results obtained by Borjas $(1995,1999)$ and Davis \& Weinstein $(2002)$, our base-case simulation assumes, for each scenario, that $\mathrm{d}\left(H^{*}+M^{*}+U^{*}\right) /(\bar{H}+\bar{M}+\bar{U})=0.12$, where $H^{*}=M^{*}=U^{*}=0$ initially. Scenario (2) is perhaps the most realistic one, as it features bimodality as well as dominance of unskilled immigrants in OECD countries. Note that in the context of the TRS regime scenario (1) is similar to Davis \& Weinstein (D\&W) in that it precludes complementarity effects between different types of labor. It is, however, different from $\mathrm{D} \& \mathrm{~W}$ in that there are non-tradable goods.

Table 1 reports on the base-case for each scenario, panel a) assuming a TRS and panel b) assuming a RIS. Figures 2 through 5 illustrate how the welfare effect varies with the size of the inflow, comparing - separately for the TRS and the RIS - the base-case where $\eta^{*}=2$ with the small country case where $\eta^{*}=\infty$. The central magnitude reported is the welfare effect, measured by the equivalent variation. This is the additional income that would be necessary - at initial prices - for natives to achieve their post-immigration level of welfare. It can be written as $E V=e\left(P_{0}^{n}, P_{0}^{x}, 1\right) \cdot\left[Y_{1}^{n} / e\left(P_{1}^{n}, P_{1}^{x}, 1\right)\right]-Y_{0}^{n}$, where subscripts 0 and 1 indicate pre- and post-immigration values. Native income $Y^{n}$ is as defined in $(6)$, and $e(\cdot)$ denotes the expenditure function. In percent of initial native income, we have

$$
\frac{E V}{Y_{0}^{n}}=\frac{Y_{1}^{n}}{e\left(P_{1}^{n}, P_{1}^{x}, 1\right)} / \frac{Y_{0}^{n}}{e\left(P_{0}^{n}, P_{0}^{x}, 1\right)}-1
$$


Finally, we also report the Gini coefficient, and the general equilibrium labor demand elasticities generated by our model, including cross-price elasticities. We organize the discussion of our findings around three core results.

Result 1: An unbalanced flow of immigrants generates a sizeable welfare gain that may compensate the DEGW-type terms-of-trade effect. Moreover, the welfare effect is nonmonotonic in the size of the inflow.

D\&W find that an immigration-induced increase in overall endowment of about $12 \%$ results in a $0.8 \%$ loss in native real income, due to a terms-of-trade deterioration. Column (1) of table 1 covers the corresponding case of proportional immigration where the complementarity term $-L^{*} g_{L L} \mathrm{~d} L^{*}$ in equation (16) is zero. In contrast to D\&W, a lower export price is coupled with a falling price of non-tradables which increases the real value of interest earnings, whence the welfare loss falls to $0.55 \%$. The loss is further reduced if immigration is bimodal, with a bias towards unskilled workers (column 2). Exports expand at a lower rate, with a more modest terms-of-trade deterioration. Combined with a beneficial complementarity effect, this brings the welfare loss down to a mere $0.15 \%$. If all immigrant labor is unskilled, then the welfare effect turns positive, with a sizable gain of $0.82 \%$. This is in stark contrast to $\mathrm{D} \& \mathrm{~W}$ who argue (section V.B) that labor heterogeneity leaves the welfare results quantitatively and qualitatively unchanged.

We have argued in section 2 that the first-order terms-of-trade effect of immigration, coupled with a second-order complementarity effect, may cause the welfare effect to be non-monotonic. Figure 2 provides evidence for this phenomenon. For high-skilled immigration, the welfare effect reaches a minimum of about $-3.15 \%$ of GDP at an inflow of $24 \%$, and then improves again for higher levels of immigration. While this trough does not lie within the reach of realistic immigration flows, the bimodal scenario features a much lower point of turnaround, at an inflow of about $12 \%$, which is roughly equal to the D\&W-magnitude. Thus, the welfare loss of $-0.15 \%$ exhibited in table 1 really is the worst possible case. This finding has important normative implications. While the D\&W result 
might suggest a more restrictive policy stance, our framework suggests that a reduction in the loss could also be obtained with an opposite policy, viz. an increase in immigration. Obviously, the empirical strategy behind these results is too rough for sweeping policy conclusions. But the principal possibility of such non-monotonicities should be recognized when formulating theory-based advice for migration policy.

Result 2: In contrast to Borjas' results, under the RIS with $\eta^{*}=\infty$, an unbalanced inflow need not be beneficial for natives, while a perfectly balanced inflow always is. Moreover, immigration tends to yield a higher welfare gain under the RIS than under the TRS.

Setting $\eta^{*}=\infty$ makes our framework comparable to Borjas $(1995,1999)$ and Bauer \& Zimmermann (1997), who consistently predict a non-negative welfare effect. In our setup, a welfare loss may arise even if $\eta^{*}=\infty$. This is explained by the first term of equation (16). Due to non-tradables, this augmented term can be negative, even if conventional complementarity holds $\left(g_{L L} \mathrm{~d} L^{*}<0\right)$. Any inflow which leads to an excess demand for non-tradables drives up $P^{n}$, with two consequences. First, since native capital income is tied down in nominal terms by international capital mobility, it falls in real terms. If this is an important enough part of native income, the associated real income loss may even dominate the picture. A second effect arises through the Stolper-Samuelson-term in equation (16), which is interpreted in proposition 2. Taken together, these two effects may dominate the standard technology-based complementarity, as evidenced by figure 4 for the case for high-skilled immigration under the TRS. Again, there is non-monotonicity, this time with a much more realistic point of turnaround. However, if high-skilled immigrants repatriate their income, as in figure 5 , demand for non-tradables is driven by native income alone, with a much lower increase in $P^{n}$.

With $\eta^{*} \rightarrow \infty$, a balanced inflow is devoid of native welfare gains under a TRS, as in figure 2. Again, with non-tradable goods income repatriation makes a big difference. Thus, figure 5 reveals that a $12 \%$ balanced inflow yields a $2 \%$ gain. If surprising at first sight, this result is easily understood. A positive welfare effect is possible only if real wages change. Under the TRS, a balanced inflow leads to a proportional expansion of production 
and demand, so that marginal productivities and prices remain constant. Therefore, real wages cannot change. Under a RIS, proportional expansion of all outputs occurs with unaltered domestic demand. Excess supply of domestic goods requires an adjustment in relative prices. While marginal productivities remain constant, the change in relative prices leads to changes in real wages, thus facilitating a welfare increase. We may call this a demand-based complementarity effect, as opposed to the technological complementarity effect, captured by $g_{L L} \mathrm{~d} L^{*}<0$ in equation (16).

Looking at figure 4, one is tempted to conclude a clear ranking of scenarios: The more immigration is dominated by unskilled labor, the larger the native welfare gain, at least for realistic magnitudes of the inflow. This is in contrast to Borjas (1995, 1999), and it works mainly through the price of non-tradable goods, as we have just pointed out. For instance, a $12 \%$ "inflow at tails" which, by definition, is biased towards unskilled labor, leads $0.15 \%$ gain. Note that this is considerably lower than the measure obtained by Borjas (1995) in an otherwise comparable setting. Hence, the additional adjustment mechanisms that we incorporate in our two-sector model (labor re-allocation, endogenous goods prices) do make a difference in terms of empirical magnitudes.

Result 3: The welfare ranking of different scenarios crucially depends on the repatriation assumption, and on the size of the inflow.

Comparing figures 2 and 3 for the case where $\eta^{*}=2$, as well as 4 and 5 for $\eta^{*}=\infty$, shows that the welfare ranking of scenarios is changed dramatically when we switch from a true residence system (TRS) to a repatriated income system (RIS). Under the TRS, unskilled immigration is most beneficial because it allows a reduction in the overall price level which augments the pure technical complementarity effect. Moreover, high-skilled immigration tends to be worst (at least for small to medium-size inflows), as this strongly deteriorates the economy's terms-of-trade. Under the RIS, however, balanced immigration dominates all other scenarios. For a given size of the inflow, output expansion is largest if immigration is balanced, and large changes in relative prices may generate substantial 
welfare gains. Our figures illustrate that the scenario ranking also depends on the size of the inflow. Consider, for instance the RIS with $\eta^{*}=2$ : For small and medium-size inflows unskilled immigration dominates, but for larger inflows perfectly balanced immigration proves better.

\subsection{Sensitivity analysis}

We would expect that our simulation results are sensitive with respect to certain parameter variations. A prime candidate is the price elasticity of export demand, where our basecase in table 1 assumes $\eta^{*}=2$. This is an unweighted average taken from a survey by Marquez (2002), who finds an interval for long-run econometric estimates ranging from 1 to $3 .^{10}$ It is interesting to note that there is very little correlation between country size and the estimated elasticity, with estimates far away from $\eta^{*} \rightarrow \infty$ even for small countries. Another important magnitude where countries might differ from our base-case is the degree of openness. Our base-case features a ratio of exports plus imports to GDP which is equal to 0.5. From the Penn World Tables 6.0, we observe a lower end of 20 percent for Japan and 26 percent for the US, while the corresponding figure for large European countries (say Germany, France or the UK) is around 60 percent, and small countries (like Austria, Belgium or the Netherlands) exhibit openness beyond 100 percent.

How do our welfare results respond to re-calibrations of our model that reflect such inter-country variation in trade elasticities and openness? Tables 2 and 3 provide some sensitivity evidence for the "inflow at tails" scenario. While table 2 looks at independent variations of each parameter for alternative sizes of the inflow, table 3 allows for simultaneous variations in both, the trade elasticity and openness. As expected, a larger value of $\eta^{*}$ reduces the welfare loss (increases the gain) for all sizes of the inflow considered, and for both the RIS and TRS. It also mitigates the non-monotonicity, as evidenced by line

\footnotetext{
${ }^{10}$ Using direct estimates of this elasticity is a notable difference between our empirical strategy and Davis \& Weinstein (2002) who use estimates of GDP-responsiveness to terms-of-trade changes in order to infer a value for the trade elasticity.
} 
3 of table 2. A similar pattern emerges if we reduce the degree of openness. Notice that smaller openness implies a larger non-tradables sector. The sensitivity analysis thus reinforces the general case made above that non-tradables open up an important channel for native welfare gains from an immigration scenario, if this is biased towards non-tradable goods, as with the "inflow at tails" which is dominated by unskilled labor. The sensitivity is more pronounced for a system where income is repatriated, since this features a more pronounced price-reaction for non-tradable goods, as argued above.

Table 3 further testifies to the importance of openness. For instance, increasing the export price elasticity to $\eta^{*}=3$ improves the welfare effect vis a vis the base-case, but if this higher value applies to a more open economy, with $1-\beta^{n}$ increasing to 0.6 , the welfare gain is reduced below the base-case. Conversely, if $\eta^{*}$ is reduced to 1 , the scenario is less favorable to natives, but if the economy also becomes less open, then this deterioration is mitigated, particularly for the RIS, although the loss still prevails. Under the RIS, a sizable gain emerges for countries that are at the same time less open and facing a higher trade elasticity. A notable feature of table 3 is that the sensitivity with respect to both, the trade elasticity and the degree of openness, is much more pronounced if income is repatriated than if migrants become true residents.

\section{Conclusions}

International labor movements are among the most important long-term challenges for economic policy in all countries that feature relatively high standards of living. Immigration policies pursued in such countries are likely to remain restrictive and selective, reflecting a policy debate which revolves around alleged positive and negative effects of immigration on the native work force, and on the general level of host-country welfare.

This paper consolidates two opposing views on how natives are affected by immigration, one emphasizing the immigration surplus coupled with wage effects (Borjas, 1995,1999), the other identifying an aggregate native welfare loss due to terms-of-trade 
effects (Davis \& Weinstein, 2002). We first develop a very general model allowing for an arbitrary number of factors and goods, in order to derive conditions for a native welfare gain from immigration. Our model combines quantitative restrictions on the stock of foreign worker-residents with endogenous physical capital stocks, assuming perfect international capital mobility, and it allows for tradable as well as non-tradable goods. The analysis augments the complementarity-based immigration surplus by incorporating endogenous adjustment of goods prices. We derive a simple equation which breaks the total change in native welfare into three parts: the traditional complementarity effect stressed by Borjas, a Stolper-Samuelson-type effect operating through goods price endogeneity, and the terms-of-trade effect highlighted by Davis \& Weinstein. While the first two channels are of second-order, the latter is a first-order effect, so that its detrimental impact on welfare dominates if the immigrant inflow is small.

We then derive additional insights and sharper results by translating our main argument into a more specific model structure featuring three skill-levels of labor. Introducing wage frontiers and labor demand functions that are augmented to incorporate repercussions from endogenous prices for exportable and non-tradable goods, we derive a number of propositions on the wage and welfare effects of alternative immigration scenarios. In various ways, these propositions set the complementarity-based immigration surplus against the exportable and non-tradable goods price effect within a unifying framework. The contradictory welfare effects reported in the aforementioned literature now emerge as special cases. Relative to the existing literature, our approach highlights the importance of adjustment mechanisms operating through reallocation of mobile (medium-skilled) labor, and through immigration-induced capital inflows. These adjustment mechanisms tend to reduce the size of the immigration surplus. At the same time, the price effect for non-tradable goods tends to increase native welfare gains, in particular if the inflow is biased towards the non-tradables sector.

A calibration-based simulation exercise reveals that these additional channels prove quantitatively important for realistic parameterizations of the model. It also reveals that, 
due to a coexistence of first-order and second-order effects, the native welfare effect is non-monotonic in the size of the labor inflow. Pursuing a numerical approach also allows us to shed light on the difference between a system where immigrant income is repatriated, and a system of true residence where all immigrant income is spent domestically. Due mainly to the existence of a non-tradable goods sector, the two systems generate vastly different native welfare effects from immigration. For a large class of scenarios considered, repatriation of immigrant income works to the advantage of natives.

Our sensitivity analysis reveals that seemingly small variations in the price elasticity of export demand and the degree of openness on goods markets have considerable consequences for how immigration affects the host country, sometimes even changing the native welfare effect in sign. The magnitude, and even the sign of the native welfare effect are quite sensitive with respect to these key parameters. While this might be interpreted as a lack of robust results, we view it as a promising way to understand why the attitudes towards immigration revealed by opinion polls, as well as actual immigration policies and econometric results vary over different countries. Countries with a lower degree of openness and a larger price elasticity of export demand appear better positioned to reap welfare gains from immigration, particularly of immigrant income is remitted. Unfavorable terms-of-trade effects may easily be compensated by an augmented complementarity-based surplus and by a favorable price effect for non-tradable goods. But, due to non-monotonicity, this may need a large size of the labor inflow.

A natural next step on the research agenda is to calibrate our model so as to capture the observed variation in the degree of openness and the price elasticity of demand, as well as the skill-distribution of inflows, in a detailed cross-country study. Comparing the simulated wage and native welfare effects might then help to explain the cross-country difference in opinion polls and policies pursued. Research in this direction, combined with a richer framework concerning labor market imperfections should also play an important role for a more explicit normative underpinning of immigration policies. 
Table 1: Simulated labor market and welfare effects of immigration

\begin{tabular}{|c|c|c|c|c|c|}
\hline & & $\begin{array}{c}(1) \\
\text { perfectly } \\
\text { balanced }\end{array}$ & $\begin{array}{l}(2) \\
\text { inflow } \\
\text { at tails }\end{array}$ & $\begin{array}{c}(3) \\
\text { high-skilled } \\
\text { only }\end{array}$ & $\begin{array}{c}(4) \\
\text { unskilled } \\
\text { only }\end{array}$ \\
\hline Change in labor supply (\%) & $\hat{H}$ & 12.0000 & 8.0000 & 40.0000 & 0.0000 \\
\hline & $\hat{M}$ & 12.0000 & 0.0000 & 0.0000 & 0.0000 \\
\hline & & 12.0000 & 32.0000 & 0.0000 & 40.0000 \\
\hline Shares in total labor & $H / L$ & 30.0000 & 28.9286 & 28.9286 & 28.9286 \\
\hline supply (\%) (a) & $M / L$ & 40.0000 & 35.7143 & 35.7143 & 35.7143 \\
\hline & $U^{\prime} / L$ & 30.0000 & 35.3571 & 35.3571 & 35.3571 \\
\hline \multicolumn{6}{|c|}{ Case a): True residence system (TRS) } \\
\hline Labor reallocation $(\%)$ & $\hat{M}^{x}$ & 11.6192 & -0.4930 & -7.1631 & 1.1469 \\
\hline Change in real wages $(\mathrm{b})$ & $\hat{W}^{m}-\hat{P}$ & -1.2768 & 4.2752 & 12.1556 & 2.2789 \\
\hline & $\hat{W}^{h}-\hat{P}$ & -1.4661 & -1.5296 & -19.1936 & 3.2987 \\
\hline & $\hat{W}^{u}-\hat{P}$ & -1.2590 & -16.9725 & 12.6766 & -21.9203 \\
\hline Change in outputs (\%) & $\hat{Q}^{x}$ & 11.8595 & 6.3838 & 36.2743 & -0.0283 \\
\hline & $\hat{Q}^{n}$ & 11.8998 & 5.7208 & 0.3592 & 6.7124 \\
\hline Change in price level (\%) (b) & $\hat{P}$ & -3.9494 & -1.8000 & 3.9538 & -3.0002 \\
\hline Rel. price (benchm.: 1.4281) & $P^{x} / P^{n}$ & 1.4282 & 1.4188 & 1.0515 & 1.5238 \\
\hline Change in welfare (\%) & $E V / Y_{0}^{n}$ & -0.5485 & -0.1460 & -2.6585 & 0.8170 \\
\hline Gini index (bench.: 0.2600) & & 0.2600 & 0.2972 & 0.2198 & 0.3142 \\
\hline Labor demand elasticities & own & & & -0.4798 & -0.5480 \\
\hline & medium & & & $\begin{array}{l}0.3039 \\
0.3169\end{array}$ & $\begin{array}{l}0.0570 \\
0.0825\end{array}$ \\
\hline \multicolumn{6}{|c|}{ Case b): Repatriated income system (RIS) } \\
\hline Labor reallocation $(\%)$ & $\hat{M}^{x}$ & 41,5944 & 12,7626 & 31,0348 & 7,7965 \\
\hline \multirow[t]{3}{*}{ Change in real wages ${ }^{(b)}$} & $\hat{W}^{m}-\hat{P}$ & $-11,6549$ & $-1,7494$ & $-4,3289$ & $-0,8078$ \\
\hline & $\hat{W}^{h}-\hat{P}$ & 6,6559 & 2,5450 & $-9,1912$ & 5,4166 \\
\hline & $\hat{W}^{u}-\hat{P}$ & $-13,1887$ & $-22,4466$ & $-6,2771$ & $-24,6067$ \\
\hline \multirow[t]{2}{*}{ Change in outputs } & $\hat{Q}^{x}$ & 13,6539 & 7,2655 & 39,2515 & $-0,4033$ \\
\hline & $\hat{Q}^{n}$ & 9,9217 & 4,8100 & $-2,1619$ & 6,2591 \\
\hline Change in price level (\%) ${ }^{(b)}$ & $\hat{P}$ & -18.3662 & -10.1160 & -17.2717 & -7.3702 \\
\hline Rel. price (benchm.: 1.4281) & $P^{x} / P^{n}$ & 1.7116 & 1.5605 & 1.3682 & 1.5994 \\
\hline Change in welfare $(\%)$ & $E V / Y_{0}^{n}$ & 0.5936 & 0.1950 & -2.6723 & 1.0188 \\
\hline Gini index (benchm.: 0.2600) & & 0.3003 & 0.3175 & 0.2366 & 0.3345 \\
\hline \multirow[t]{2}{*}{ Labor demand elasticities } & own & & & -0.2298 & -0.6152 \\
\hline & $\begin{array}{l}\text { medium } \\
\text { opposite }\end{array}$ & & & $\begin{array}{l}-0.1082 \\
-0.1569\end{array}$ & $\begin{array}{r}-0.0202 \\
0.1354\end{array}$ \\
\hline
\end{tabular}

Legend: For easy comparison, we specify all scenarios such that the overal size of the inflow is $12 \%$ of the original native labor force. The underlying elasticity of export demand is $\eta^{*}=2$, and the benchmark degree of openness is 0.5 . See the main text and table A.2 for more details on the calibration procedure. (a): $L=H+M+U$. (b): $P$ denotes the unit-level of the expenditure function. 
Table 2: Sensitivity analysis for "inflow at tails"

Equivalent variation (in \%)

\begin{tabular}{|c|c|c|c|c|c|c|c|c|}
\hline & \multicolumn{8}{|c|}{ Size of inflow (\%) } \\
\hline & \multicolumn{2}{|c|}{$6 \%$} & \multicolumn{2}{|c|}{$12 \%$} & \multicolumn{2}{|c|}{$18 \%$} & \multicolumn{2}{|c|}{$24 \%$} \\
\hline & TRS & RIS & TRS & RIS & TRS & RIS & TRS & RIS \\
\hline & \multicolumn{8}{|c|}{ Openness: $1-\beta^{n}=0.5$} \\
\hline Export elasticity: $\eta^{*}=1$ & -0.36 & -0.74 & -0.61 & -1.11 & -0.80 & -1.27 & -0.94 & -1.30 \\
\hline$\eta^{*}=2$ & -0.12 & 0.01 & -0.15 & 0.19 & -0.13 & 0.46 & -0.08 & 0.79 \\
\hline$\eta^{*}=3$ & -0.05 & 0.21 & -0.03 & 0.55 & 0.01 & 0.94 & 0.10 & 1.36 \\
\hline & \multicolumn{8}{|c|}{ Export elasticity: $\eta^{*}=2$} \\
\hline \multirow{3}{*}{ 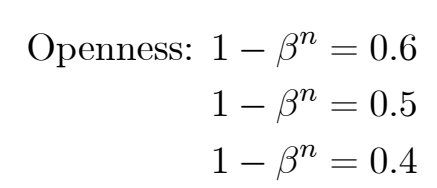 } & -0.15 & -0.18 & -0.27 & -0.22 & -0.32 & -0.17 & -0.35 & -0.07 \\
\hline & -0.10 & 0.01 & -0.15 & 0.19 & -0.14 & 0.46 & -0.08 & 0.79 \\
\hline & -0.06 & 0.22 & -0.03 & 0.65 & 0.06 & 1.17 & 0.20 & 1.75 \\
\hline
\end{tabular}

Legend: "inflow at tails": $80 \%$ unskilled and $20 \%$ skilled labor; size of total inflow measured in \% of native labor force. TRS: true residence system. RIS: repatriated income system. Boldfaced entries indicate base-case results. $\beta^{n}$ is the share of expenditure (and production) that falls on non-tradable goods. Assuming that half of the expenditure on tradables is spent on imports and imposing balanced trade, the degree of openness, which is defined as total trade over GDP, corresponds to $1-\beta^{n}$.

Table 3: Sensitivity Analysis for "inflow at tails" Equivalent variation (in \%)

\begin{tabular}{|c|c|c|c|c|c|c|}
\hline & \multicolumn{6}{|c|}{ Openness: $1-\beta^{n}$} \\
\hline & \multicolumn{2}{|c|}{0.6} & \multicolumn{2}{|c|}{0.5} & \multicolumn{2}{|c|}{0.4} \\
\hline & TRS & RIS & TRS & RIS & TRS & RIS \\
\hline Export elasticity: $\eta^{*}=1$ & -1.01 & -1.87 & -0.61 & -1.11 & -0.56 & -0.68 \\
\hline$\eta^{*}=2$ & -0.27 & -0.22 & -0.15 & 0.19 & -0.03 & 0.65 \\
\hline$\eta^{*}=3$ & -0.23 & 0.07 & -0.03 & 0.55 & -0.05 & 0.88 \\
\hline
\end{tabular}

Legend: Simulations for base-case size of the inflow: $12 \%$ of total native labor force. TRS: true residence system. RIS: repatriated income system. Boldfaced entries indicate base-case results. On $\beta^{n}$, see the previous table. 


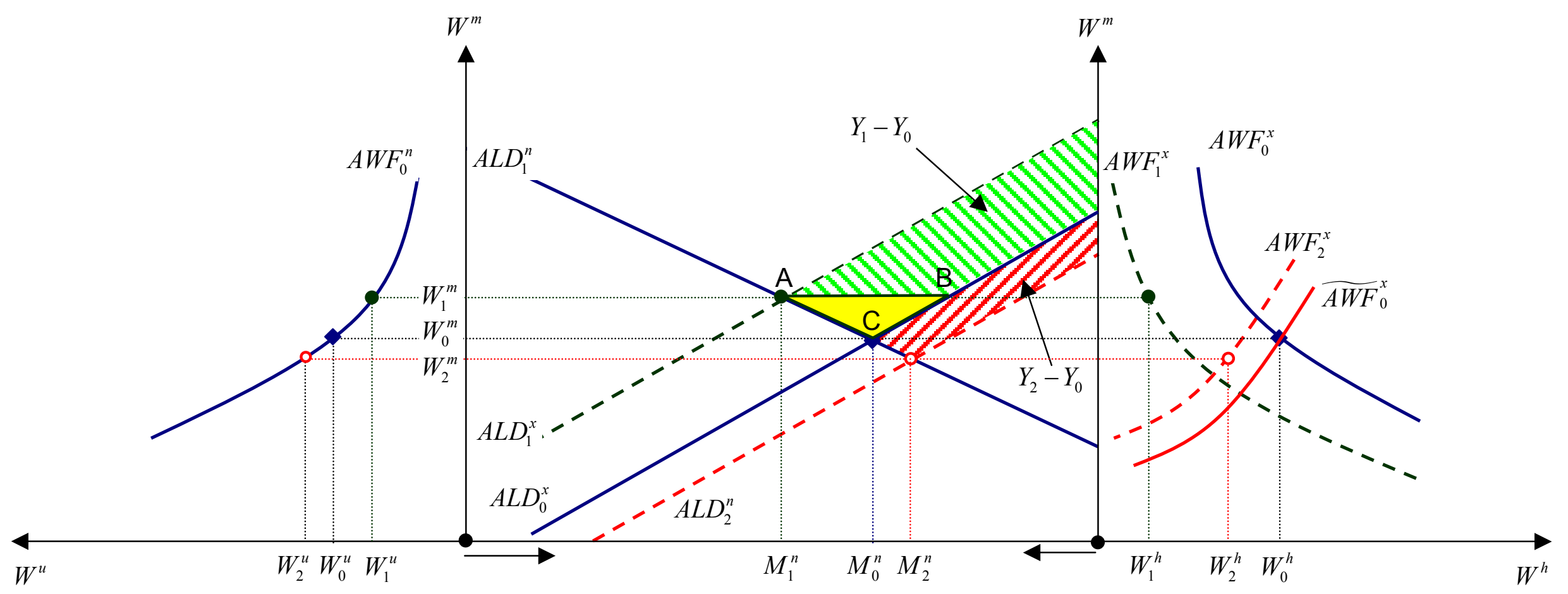

Figure 1: The wage and welfare effects of immigration. 


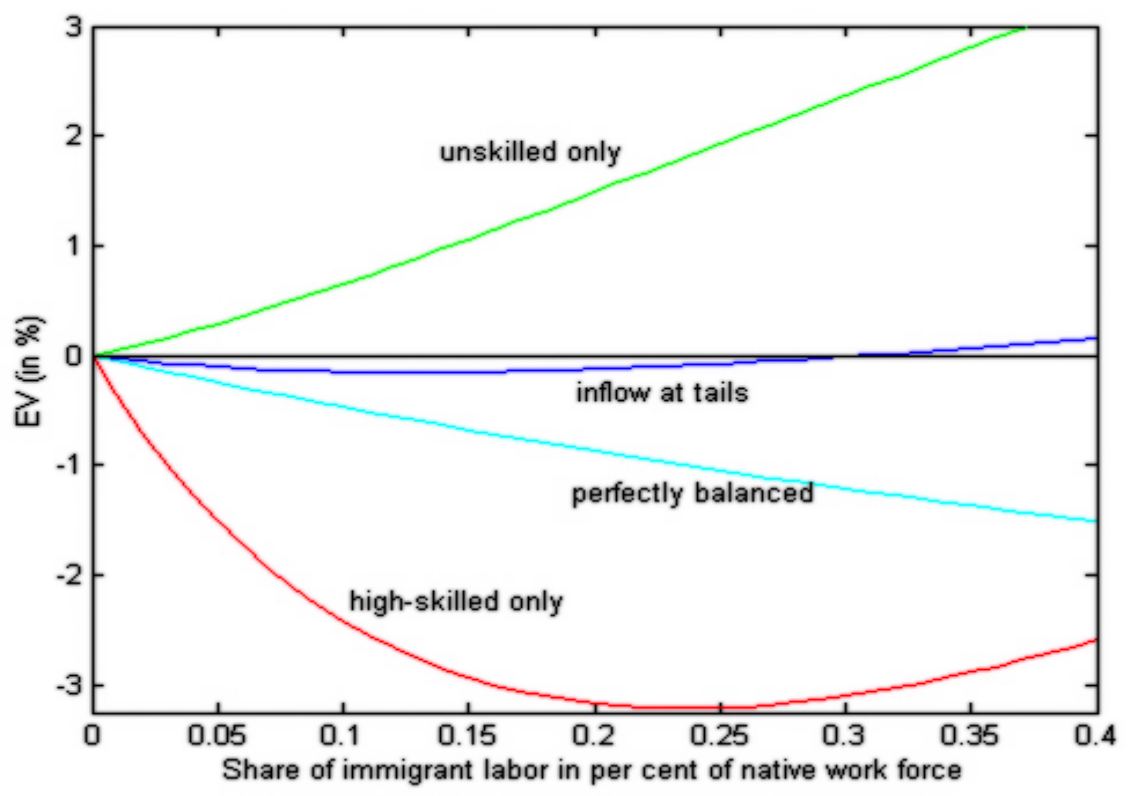

Figure 2: Welfare effects of different scenarios $\left(\right.$ TRS, $\left.\eta^{x}=2\right)$

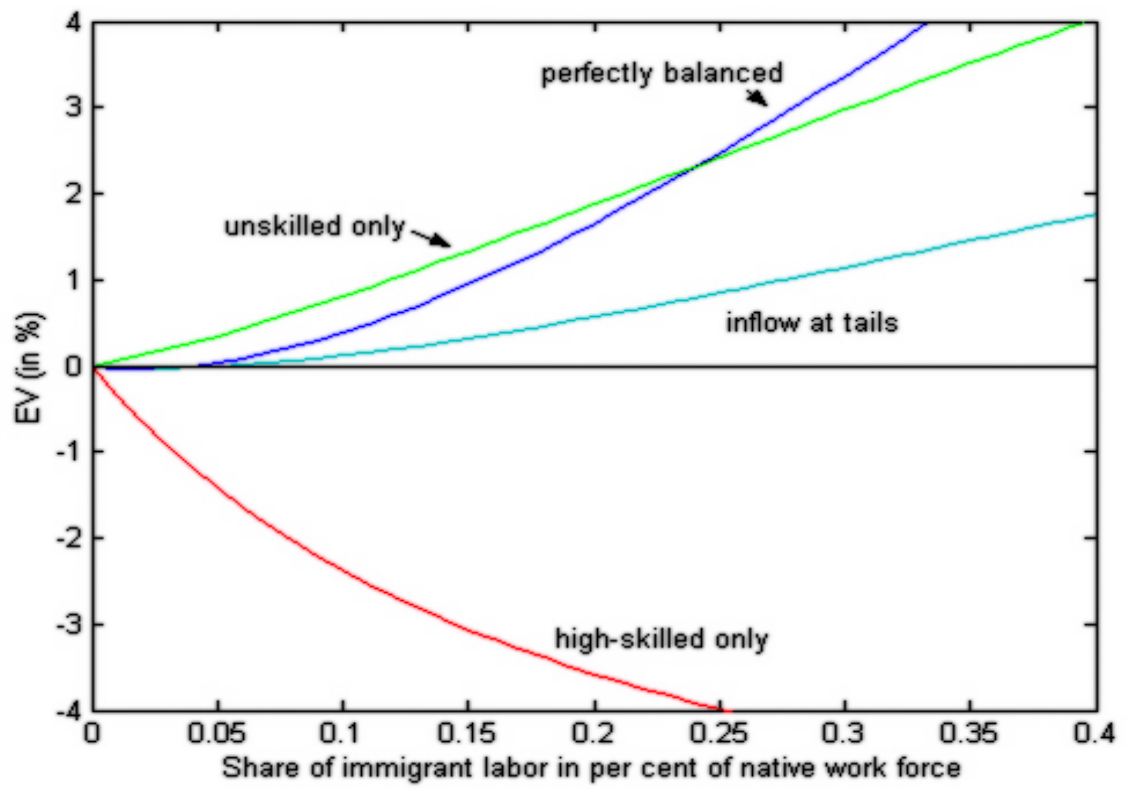

Figure 3: Welfare effects of different scenarios $\left(\right.$ RIS, $\left.\eta^{x}=2\right)$ 


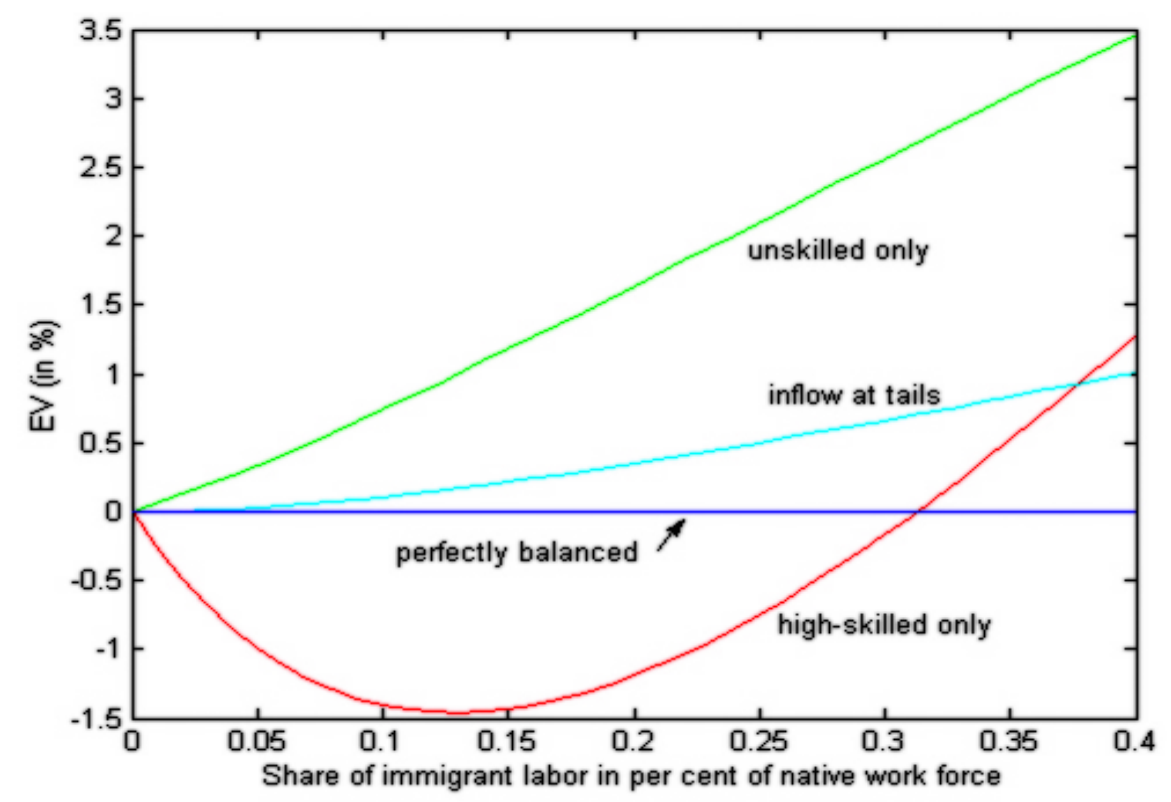

Figure 4: Welfare effects of different scenarios (TRS, $\eta^{x}=\infty$ )

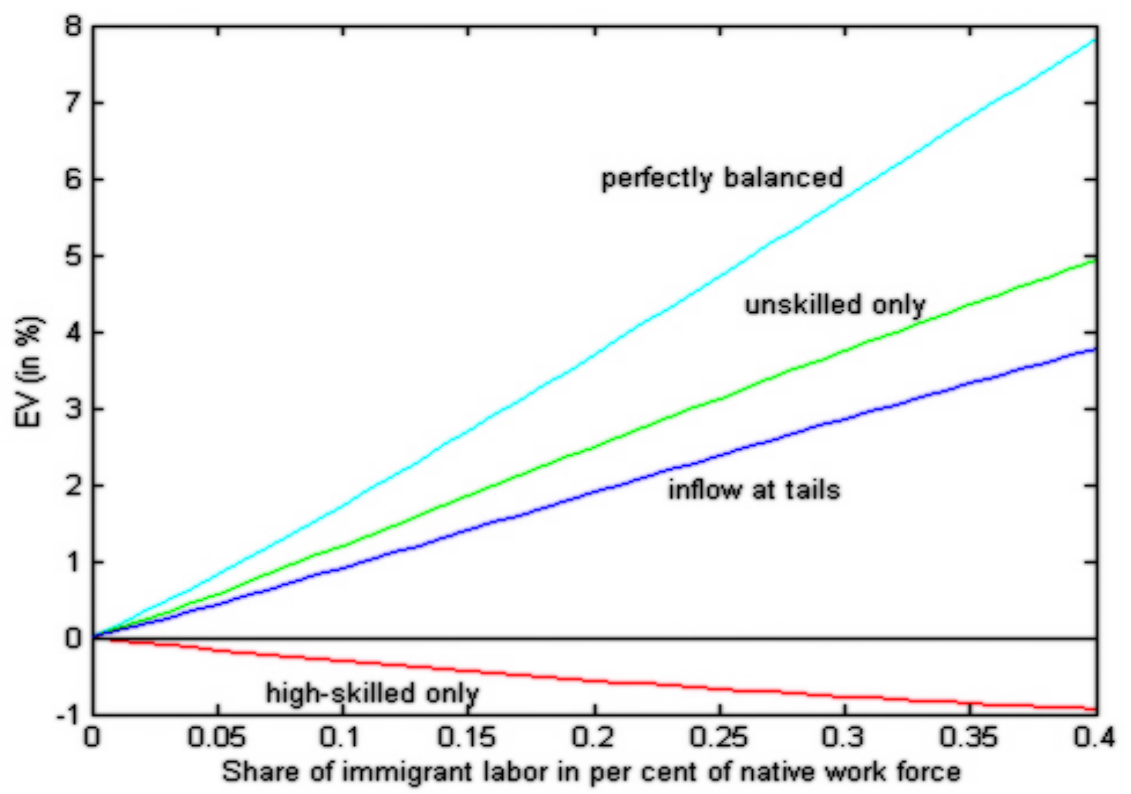

Figure 5: Welfare effects of different scenarios (RIS, $\left.\eta^{x}=\infty\right)$ 


\section{Appendix: Full solution - endogenous expenditure}

It proves convenient both for derivation and interpretation to decompose the general equilibrium elasticities according to

$$
\Gamma_{n x}=\Omega_{n x}+\Omega_{n E} \Xi_{E x}
$$

where $n$ indicates an endogenous variable, with $n=M^{n}, W^{h}, W^{m}, W^{u}$, and $x$ indicates an exogenous variable, whereby we focus on immigration of high- and unskilled labor only, i.e., $x=H, U$. The elasticities $\Omega_{n x}$ emerge from solving the subsystem (23) through (26). They are the ones that we focuse on in the analysis of section 3 in the text. In this appendix, we derive the terms $\Omega_{n E} \Xi_{E x}$ which capture the added interdependence arising from endogenous expenditure. $\Omega_{n E}$ measures the dependence of factor prices on aggregate expenditure, derived by complete analogy to $\Omega_{n x}$ from $(23)-(26) . \Xi_{E x}$ measures the effect of exogenous endowment changes on aggregate expenditure. Under TRS, this combines the direct effect from an immigration-induced increase in the work force, and the indirect effect of an immigration-induced change in domestic factor prices. Under RIS, domestic expenditure is affected via factor price changes alone; see equation (17). Since domestic expenditure, in turn, affects factor prices this generates a complex interdependence.

In matrix form, we may write the full system as

$$
\left[\begin{array}{l}
\hat{M}^{n} \\
\hat{W}^{u} \\
\hat{W}^{m} \\
\hat{W}^{h}
\end{array}\right]=\left[\Omega_{n x}\right] \cdot\left[\begin{array}{c}
\hat{U} \\
\hat{H}
\end{array}\right]+\left[\Omega_{n E}\right] \cdot\left\{\left[\Phi_{E n}\right] \cdot\left[\begin{array}{c}
\hat{M}^{n} \\
\hat{W}^{u} \\
\hat{W}^{m} \\
\hat{W}^{h}
\end{array}\right]+\left[\Phi_{E x}\right] \cdot\left[\begin{array}{c}
\hat{U} \\
\hat{H}
\end{array}\right]\right\},
$$

where $\left[\Omega_{n x}\right](4 \times 2)$ and $\left[\Omega_{n E}\right](4 \times 1)$ are elasticities emerging from the solution of $(23)$ through $(26)$, and $\left[\Phi_{E n}\right](1 \times 4)$ and $\left[\Phi_{E x}\right](1 \times 2)$ are elasticities obtained from the differentiated equation (17). Under RIS we have $\Phi_{E x}=0$. Notice the difference between $\Phi_{E x}$ and $\Xi_{E x}$ which captures the full general equilibrium interdependence. The solution is then 
obtained as

$$
\left[\begin{array}{c}
\hat{M}^{n} \\
\hat{W}^{u} \\
\hat{W}^{m} \\
\hat{W}^{h}
\end{array}\right]=\left\{\mathbf{I}-\left[\Omega_{n E}\right] \cdot\left(\left[\Phi_{E n}\right]+\left[\Phi_{E x}\right]\right)\right\}^{-1} \cdot\left[\Omega_{n x}\right] \cdot\left[\begin{array}{c}
\hat{U} \\
\hat{H}
\end{array}\right]=\left[\Gamma_{n x}\right] \cdot\left[\begin{array}{c}
\hat{U} \\
\hat{H}
\end{array}\right]
$$

where $\left[\Gamma_{n x}\right] \equiv\left\{\mathbf{I}-\left[\Omega_{n E}\right] \cdot\left(\left[\Phi_{E n}\right]+\left[\Phi_{E x}\right]\right)\right\}^{-1} \cdot\left[\Omega_{n x}\right]$ is the matrix of general equilibrium elasticities according to the decomposition in (28). Table A.1 presents $\left[\Omega_{n x}\right],\left[\Omega_{n E}\right]$ and $\left[\Phi_{E n}\right]$, which allows derivation of the general equilibrium elasticities $\left[\Gamma_{n x}\right]$. The additional interdependence generated by endogenous expenditure, relative to the simple case of section 3 where $E$ is treated as exogenous, i.e. the terms $\Omega_{n E} \Xi_{E x}$ in (28), can then be identified by comparing elasticities $\Gamma_{n x}$ with $\Omega_{n x}$.

Given solutions $\hat{W}^{l}=\Gamma_{W^{l} U} \hat{U}+\Gamma_{W^{l} H} \hat{H}, l=(h, m, u)$, we may finally turn to native welfare. Using (11), we write $\hat{V}=\hat{Y}^{n}-\beta^{n} \hat{P}^{n}-\beta^{x} \hat{P}^{x}$, where $Y^{n}$ is native income as defined in (6), and $\beta^{n}$ and $\beta^{x}$ are budget shares in domestic consumption. These emerge from (11), invoking Roy's identity, and normalizing $v_{E}=1$. Notice that in our case good $X$ is the only tradable good which changes in price. In turn, the change in native income may be written as $\hat{Y}^{n}=\bar{\gamma}^{h} \hat{W}^{h}+\bar{\gamma}^{u} \hat{W}^{u}+\bar{\gamma}^{m} \hat{W}^{m}$, where $\bar{\gamma}^{h}=W^{h} \bar{H} / Y^{n}$ is the share of native high-skilled labor income in $Y^{n}$, and analogously for $l=m$ and $l=u$. Inserting the above solutions for $\hat{W}^{l}$ we would find out that $\hat{V}=0$, if there are no pre-existing stocks of foreign labor, $H^{*}=M^{*}=U^{*}=0$, which rules out any marginal complementarity effect, and if there is no terms-of-trade effect. The magnitude of welfare effects from terms-of-trade changes, if any, depends on the share of exports in $Y^{n}$. All of this has already been shown for a much more general case in section 2 above and need not be reiterated for this special model. For discrete labor inflows, complementarity effects do arise and changes in the non-tradable goods price obtain welfare significance, in addition to the first-order terms-of-trade effect. Section 4 which takes a numerical perspective pins down these welfare effects by means of the usual equivalent variation measure. 
Table A.1: Decomposition of general equilibrium elasticities $\Gamma_{n x}=\Omega_{n x}+\Omega_{n E} \Xi_{E x}$

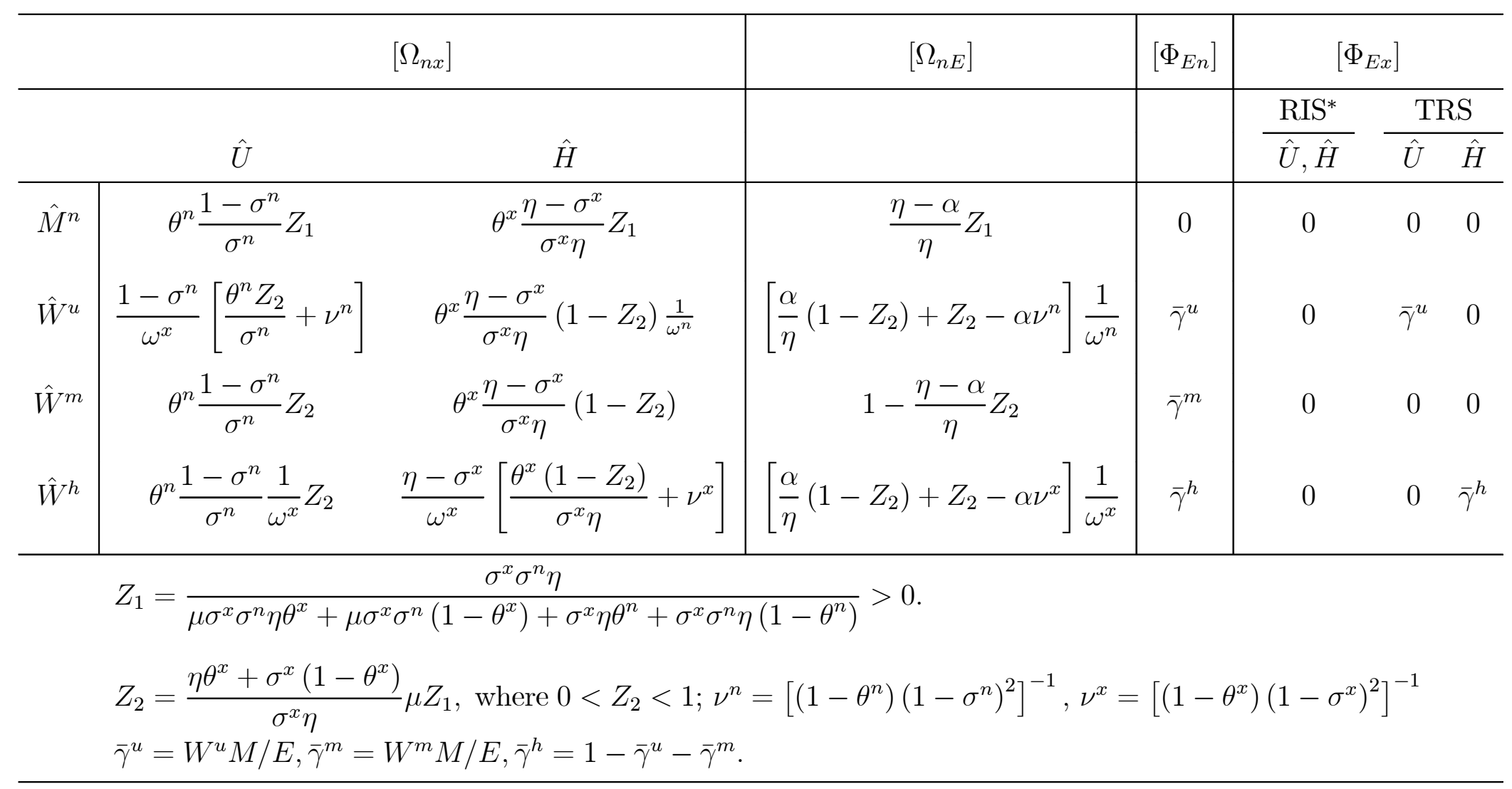

$n$ : endogenous variables, $n=M^{n}, W^{h}, W^{m}, W^{u} . x$ : exogenous variables, $x=H, U$. *: $\left[\Phi_{E x}\right]=0$ for both $U$ and $H$. 
Table A.2: Calibration and benchmark equilibrium

\begin{tabular}{|c|c|c|c|c|}
\hline & $\begin{array}{l}\text { functional forms } \\
\text { and parameters }\end{array}$ & quantities & prices & $\begin{array}{l}\text { empirical restriction } \\
\text { or source }\end{array}$ \\
\hline $\begin{array}{l}\text { household utility } \\
\text { non-tradable good } \\
\text { exportable good }\end{array}$ & $\begin{array}{c}u=\left(D^{x}\right)^{\beta^{x}}\left(D^{n}\right)^{\beta^{*}} \\
\beta^{n}=0.5 \\
\beta^{x}=0.25 \\
D^{x *}=D_{0}^{x *}\left(P^{x}\right)^{-\eta^{*}} \\
\eta^{*}=2 \\
\beta^{z}=0.25\end{array}$ & $\begin{aligned} &\left(D^{z}\right)^{\beta^{z}} \\
& D^{n}=0.4315 \\
& D^{x}=0.1508 \\
& D^{x *}=0.1508 \\
& D^{z}=0.1909 \\
&\left(D^{x}\right.\end{aligned}$ & $\begin{array}{c}e\left(P^{x}, P^{n}, P^{z}, 1\right)=0.9978 \text { (a) } \\
P^{n}=0.8849 \\
P^{x}=1.2661 \\
\\
P^{z}=1 \\
\left.P^{x}+D^{z}\right) / E=0.5\end{array}$ & $\begin{array}{l}\beta^{n(\mathrm{~b})} ; D^{n}, P^{n} \text { calibrated } \\
\beta^{x(\mathrm{~b})} ; D^{x}, P^{x} \text { calibrated } \\
\text { calibrated } \\
\text { taken from Marquez }(2002) \\
\beta^{z}, P^{z} \text { by normaliz., } D^{z} \text { calibr. }\end{array}$ \\
\hline \multicolumn{5}{|l|}{ technology: nested CES } \\
\hline $\begin{array}{l}\text { exportable good } \\
\text { med.-skilled wage share } \\
\text { non-tradable good } \\
\text { med.-skilled wage share } \\
\text { capital share } \\
\text { capital-labor-substitution } \\
\text { labor-skill-substitution }\end{array}$ & $\begin{array}{c}Q^{x}=F^{x}\left[K^{x} L^{x}\left(H, M^{x}\right)\right] \\
\theta^{x}=0.8489 \\
Q^{n}=F^{n}\left[K^{n} L^{n}\left(U, M^{x}\right)\right] \\
\theta^{n}=0.1523 . \\
\theta_{K}^{n}=\theta_{K}^{n}=0.3 \\
\sigma_{K L}^{x}=\sigma_{K L}^{n}=0.7 \\
\sigma^{x}=\sigma^{n}=1.242\end{array}$ & $\begin{array}{l}Q^{x}=0.3016 \\
Q^{n}=0.4315\end{array}$ & $\begin{array}{l}P^{x}=1.2661 \\
P^{n}=0.8849\end{array}$ & $\begin{array}{l}\text { calibrated, } Q^{x} \text { net of deprec. } \\
\text { calibrated } \\
\text { calibrated, } Q^{n} \text { net of deprec. } \\
\text { calibrated } \\
\text { based on Backus et al. (1994) } \\
\text { based on Abreu et al. (2003) } \\
\text { calibrated (c) }\end{array}$ \\
\hline GDP $^{(\mathrm{d})}$ & & \multicolumn{2}{|c|}{$Y=P^{x} Q^{x}+P^{n} Q^{n}=0.7636$} & net of deprec. \\
\hline
\end{tabular}


Table A.2: Calibration and benchmark equilibrium (continued)

\begin{tabular}{|c|c|c|c|c|}
\hline & $\begin{array}{l}\text { functional forms } \\
\text { and parameters }\end{array}$ & quantities & prices & $\begin{array}{l}\text { empirical restriction } \\
\text { or source }\end{array}$ \\
\hline \multicolumn{5}{|c|}{ capital endowment and allocation } \\
\hline capital, non-tradable sector & $P^{n} F_{K}^{n}(\cdot)=\bar{R}$ & $K^{n}=1.5272$ & $\bar{R}=i^{*}+\delta=0.15^{(\mathrm{e})}$ & $\bar{R}$ specified, $K^{n}$ calibrated \\
\hline $\begin{array}{l}\text { capital, exportable sector } \\
\text { foreign capital }\end{array}$ & $P^{x} F_{K}^{x}(\cdot)=\bar{R}$ & $\begin{array}{c}K^{x}=1.5272 \\
K^{n *}=K^{x *}=0\end{array}$ & $\bar{R}=i^{*}+\delta=0.15^{(\mathrm{e})}$ & $\begin{array}{l}\bar{R} \text { specified, } K^{x} \text { calibrated } \\
\text { assumption }\end{array}$ \\
\hline \multicolumn{5}{|c|}{ labor endowment and allocation } \\
\hline work force & & $H+M+U=1$ & & normalization \\
\hline foreign resident workers & & $H^{*}=M^{*}=U^{*}=0$ & & assumption \\
\hline high-skilled labor & & $H=0.30$ & $W^{h}=0.9853$ & $\gamma^{h}=0.47^{(\mathrm{f})}$ \\
\hline medium-skilled labor & & $M=0.40$ & $W^{m}=0.6761$ & $\gamma^{m}=0.43^{(\mathrm{f})}$ \\
\hline$M$-allocation & & $M^{x}=0.03$ & & calibrated \\
\hline unskilled labor & & $U=0.30$ & $W^{u}=0.2096$ & $\gamma^{u}=0.10^{(\mathrm{f})}$ \\
\hline
\end{tabular}

(a): $e(\cdot)$ denotes the expenditure function. (b): based on Penn World Tables Mark 6; the implication is that $\alpha=0.5$ (share of $X$ production exorted). $\gamma^{h}$ : share of high-skilled labor income in aggregate labor income: $W^{h} H /\left(W^{h} H+W^{m} M+W^{u} U\right)$; analogously for $\gamma^{m}$ and $\gamma^{u}=1-\gamma^{h}-\gamma^{m}-\gamma^{k}$, where $\gamma^{k}$ indicates the capital income share determined from $\bar{K}$ and $\bar{R}$; see above. (c): $\sigma^{n}$ and $\sigma^{x}$ calibrated to ensure an overall general equilibrium elasticity of substitution between $H$ and $U$ equal to $\sigma_{H U}=1.4$; see Katz $\&$ Autor (2000). (d): net of depreciation $\delta K$. (d): $i^{*}$ : world interest rate; $\delta$ : rate of capital depreciation. (f): labor endowments $H, M$ and $U$, as well as wage rates have been calibrated simultaneously, using information on the skill distribution of the labor force, the functional distribution of wage income $\left(\gamma^{h}, \gamma^{m}, \gamma^{u}\right)$ and a Gini-coefficient equal to 0.26; see OECD (2001). The calibration procedure is similar in many respects to Davis \& Weinstein (2002), a notable difference being that we use direct estimates for the export demand elasticity, while D\&W infer this paramter from evidence on the terms-of-trade responsiveness to variations in GDP. 


\section{References}

[1] Abreu Pessoa, S., S. Matos Pessoa and R. Rob, "Elasticity of Substitution Between Capital and Labor: a Panel Data Approach," Ensaios Economicos 494 (2003).

[2] Backus, D., P. Kehoe and F.E. Kydland, "International Business Cycles: Theory and Evidence," in R. Van der Ploeg, ed., Handbook of International Macroeconomics (London: Blackwell, 1994), 62-96.

[3] Bauer, Th. And K.F. Zimmermann, "Looking South and East: Labor Market Implications of Migration in Europe and LDCs," in O. Memedovic, A. Kuyenhoven and W.T.M. Molle, eds., Globalisation and Labor Markets. Challanges, Adjustment and Policy Responses in the EU and the LDCs (Boston, London: Dordrecht, 1997), $75-103$

[4] Berry, A.R. And R. Soligo, "Some Welfare Aspects of International Migration," The Journal of Political Economy 7 (1969), 778-794.

[5] Bhagwati, J.N. And T.N. SRinivasan, "On the Choice between Capital and Labour Mobility," Journal of International Economics 14 (May 1983), 209-221.

[6] Bilal, S., J.-M. Grether and J. De Melo, "Attitudes Towards Immigration: A Trade Theoretic Approach," Review of International Economics, 11 (May 2003), $253-267$.

[7] BorJas, G.J., "The Economics of Immigration," Journal of Economic Literature 32 (December 1994), 1667-1717.

[8] BorJas, G.J., "The Economic Benefits from Immigration," The Journal of Economic Perspectives 9 (Spring 1995), 3-22.

[9] Borjas, G.J., "The Economic Analysis of Immigration," in O. Ashenfelter and D. Card, eds., Handbook of Labor Economics 3A (Amsterdam: Elsevier Science BV, 1999), Ch. 28. 
[10] Borjas, G.J., "Comments," in T. Boeri, G. Hanson and B. McCormick, eds., Immigration Policy and the Welfare System (Oxford: Oxford University Press, 2002), 289-302.

[11] Borjas, G.J., "The Labor Demand Curve Is Downward Sloping: Reexamining the Impact if Immigration on the Labor Market," The Quarterly Journal of Economics 118 (November 2003), 1335-1374.

[12] Brücker, H., G.S. Epstein, B. McCormick, G. Saint-Paul, A. Venturini and K. Zimmermann, "Managing Migration in the European Welfare State" in T. Boeri, G. Hanson and B. McCormick, eds., Immigration Policy and the Welfare System (Oxford: Oxford University Press, 2002), 65-157.

[13] CARD, D., "Immigrant Inflows, Native Outflows, and the Local Labor Market Impacts of Higher Immigration," Journal of Labor Economics 19 (January 2001), 22-64.

[14] Chami, R., C. Fullenkamp and S. Jahjah, "Are Immigrant Remittance Flows a Source of Capital for Development?" Working Paper No. 03/189, IMF, September 2003.

[15] Chiswick, B.R., and T.J. Hatton, "International Migration and the Integration of Labor Markets," in M.D. Bordo, A.M. Taylor and J.G. Williamson, eds., Globalization in Historical Perspective (Chicago: The University of Chicago Press, 2003), 65-117.

[16] Davis, D.R. And D.E. Weinstein, "Technological Superiority and the Losses from Migration," Working Paper No. 8971, NBER, 2002.

[17] De New, J. and K.F. Zimmermann, "Native Wage Impacts of Foreign Labor: A Random Effects Panel Analysis," Journal of Population Economics 7 (June 1994), 177-192. 
[18] Dimaranan, B.V. And R.A. McDougall, "Global Trade, Assistance and Production: The GTAP 5 Data Base," Center for Global Trade Analysis, Purdue University, 2002.

[19] Engerman, S.L. And R.W. Jones, "International Labor Flows and National Wages," The American Economic Review 87 (May 1997), 200-204.

[20] Ethier, W.J., "International Trade and Labor Migration," The American Economic Review 75 (September 1985), 691-707.

[21] Friedberg, R.M. And J. Hunt, "The Impact of Immigrants on Host Country Wages, Employment and Growth," The Journal of Economic Perspectives 9 (Spring 1995), 23-44.

[22] Glytsos, N., "Determinants and Effects of Migrant Remittances: A Survey," in S. Djajic, ed., International Migration: Trends, Policies, and Economic Impact (London: Routledge, 2001), 250-268.

[23] Hanson, G.H., K.F. Scheve, M.J. Slaughter and A. Spilimbergo, "Immigration and the US Economy: Labour-Market Impacts, Illegal Entry, and Policy Choices," in T. Boeri, G. Hanson and B. McCormick, eds., Immigration Policy and the Welfare System (Oxford: Oxford University Press, 2002), 169-285.

[24] Jasso, G., M.P. Rosenzweig and J.P. Smith, "The Earnings of US Immigrants: World Skill Prices, Skill Transferability and Selectivity," Working Paper, Rand Corporation, 2002.

[25] Jones, R.W., "Comment" in R. Dornbusch and J.A. Frenkel, eds., International Economic Policy: Theory and Evidence (Baltimore, London: Johns Hopkins University Press, 1979), 105-111.

[26] Katz, L.F. And D.H. Autor, "Changes in the Wage Structure and Earnings Inequality," in O. Ashenfelter and D. Card, eds., Handbook of Labor Economics 3A (Amsterdam: Elsevier Science BV, 1999), Ch. 26. 
[27] Marquez, J., "Estimating Trade Elasticities," Advanced Studies in Theoretical and Applied Econometrics 39 (Boston: Kluwer, 2002).

[28] MÜller, T., "Migration, Unemployment and Discrimination," European Economic Review 47 (June 2003), 409-427.

[29] Mussa, M., "Tariffs and the Distribution of Income: The Importance of Factor Specificity, Substitutability, and Intensity in the Short and Long Run," The Journal of Political Economy 82 (1974), 1191-1203.

[30] Neary, J.P., "International Factor Mobility, Minimum Wage Rates and Factor Price Equalization: A Synthesis," The Quarterly Journal of Economics 100 (August 1985), $551-570$.

[31] OECD, Employment Outlook (Paris: OECD, June 2001).

[32] Razin, A. And E. SAdkA, "International Migration and International Trade," in M.K. Rosenzweig and O. Stark, eds., Handbook of Population and Family Economics 1B (Amsterdam: Elsevier Science BV, 1997), Ch. 15.

[33] Razin, A. ANd E. SAdKA, Labor, Capital, and Finance: International Flows (Cambridge: Cambridge University Press, 2001).

[34] O’Rourke, K.H. and J.G. Williamson, Globalization and History: The Evolution of a Nineteenth-Century Atlantic Economy, (Cambridge, MA: MIT Press, 1999).

[35] Srinivasan, T.N., "International Factor Movements, Commodity Trade and Commercial Policy in a Specific Factor Model," Journal of International Economics 14 (May 1983), 289-312. 